\title{
Role of PARP-catalyzed ADP-ribosylation in the crosstalk between DNA strand breaks and epigenetic regulation.
}

Haser H. Sutcu ${ }^{1,2, \dagger}$, Elie Matta1, ${ }^{1,2, \dagger}$, and Alexander A. Ishchenko ${ }^{1,2, *}$

${ }^{1}$ Groupe «Réparation de l'ADN», Equipe Labellisée par la Ligue Nationale contre le Cancer, CNRS UMR 8200, Univ. Paris-Sud, Université Paris-Saclay, F-94805 Villejuif, France

${ }^{2}$ Gustave Roussy, Université Paris-Saclay, F-94805 Villejuif, France

${ }^{\dagger}$ H.H.S. and E.M. contributed equally to this work

Correspondence to Alexander A. Ishchenko: Alexander.Ishchenko@gustaveroussy.fr; Tel.: +33 142115405; Fax: +33 142115008

\section{Keywords:}

programmed DNA breaks; DNA and RNA ADP-ribosylation; DNA demethylation; readers of ADP-ribosylated targets; regulation of transcription

\section{Abbreviations used:}

5caC, 5-carboxyl; 5hmC, 5-hydroxymethyl-cytosine; 5mC, 5-methylcytosine; ADPr, ADPribose; AID, activation-induced cytidine deaminase; APOBEC, apolipoprotein B mRNA-editing catalytic polypeptide-like; APLF, aprataxin and PNK-like factor; ARTD, diphtheria toxin-like ADP-ribosyl-transferases; BER, base excision repair; BRCT, BRCA1 C-terminal; CAD, caspase-activated DNase; CDK, cyclin-dependent kinase; CGI, CpG island; CHFR, checkpoint with forkhead-associated and ring domain; CSR, class switch recombination; DNMT, DNA methyltransferase; DSB, double-strand DNA break; FHA, fork head-associated; HR, homologous recombination; MAR, monomer of ADP-ribose; MMR, mismatch repair; NAD+, nicotinamide adenine dinucleotide; NF-kB, nuclear factor kappa B; NHEJ, non-homologous end-joining; OB fold, oligonucleotide/oligosaccharide-binding fold; PAR, polymers of ADP- 
ribose; PARG, poly(ADP-ribose) glycohydrolase; PARP, Poly(ADP-ribose) polymerases; PBM, poly(ADP-ribose) binding motif; PBZ, poly(ADP-ribose) binding zinc finger; PPARY, peroxisome proliferator activated receptor $\mathrm{y}$; PTM, posttranslational modification; RRM, RNA recognition motif; SSB, single-strand DNA break; ssDNA, single-stranded DNA; snoRNA, small nucleolar RNA; TET, ten-eleven translocation; UNG, uracil-N-glycosylase; TOP1, DNA topoisomerase I; TOP2, DNA topoisomerase II. 


\section{Abstract}

Covalent linkage of ADP-ribose units to proteins catalyzed by poly(ADP-ribose) polymerases (PARPs) plays important signaling functions in a plethora of cellular processes including DNA damage response, chromatin organization, and gene transcription. Poly- and mono-ADPribosylation of target macromolecules are often responsible both for the initiation and for coordination of these processes in mammalian cells. Currently, the number of cellular targets for ADP-ribosylation is rapidly expanding, and the molecular mechanisms underlying the broad substrate specificity of PARPs present enormous interest. In this review, the roles of PARPmediated modifications of protein and nucleic acids, the readers of ADP-ribosylated structures, and the origin and function of programmed DNA strand breaks in PARP activation, transcription regulation, and DNA demethylation are discussed.

\section{Introduction}

In most of living organisms, in response to environmental stress, cascades of molecular events are induced that involve specific changes in the cell's key macromolecules, such as proteins, nucleic acids, and lipids. These modifications are various chemical and structural transformations that enable to diversify the restrained genetic information encoded in DNA by the addition of chemical moieties, such as phosphate, acyl (methyl and acetate) groups, small peptides, and sugar residues on proteins and methyl group and its oxidized forms on nucleobases in DNA [1,2]. DNA damage poses a serious threat to genome integrity. Highly dynamic posttranslational and postreplicative modifications of proteins and DNA, respectively, are critical for DNA damage recognition and repair and for associated signaling [3]. In eukaryotes, ADP-ribosylation is a highly conserved posttranslational modification (PTM) of 
proteins involved in the regulation of stress responses, cell division, transcription, and protein degradation. This reaction is catalyzed by ADP-ribosyltransferases using nicotinamide adenine dinucleotide $\left(\mathrm{NAD}^{+}\right)$as a source of ADP-ribose (ADPr) moiety. The largest family of ADPribosyltransferases in eukaryotes are poly(ADP-ribose) polymerases (PARPs) that catalyze the synthesis of monomers or polymers of ADPr (MARs or PARs, respectively) covalently attached to acceptor targets (Figure 1) [4,5]. Free nonattached PAR can also function in the cell stress responses including DNA damage, heat shock, and cytoplasmic stress response $[4,6]$. Importantly, the cellular turnover of PAR is regulated by PAR glycohydrolase (PARG), which degrades the polymer by hydrolysis of ribose-ribose bonds [7]. ADP-ribose (ADPr)based modifications of target nuclear proteins including histones provide an efficient chromatin-remodeling mechanism required for efficient repair of DNA strand breaks, yet-in the case of severe genotoxic stress-PARP-catalyzed modifications of cell content may direct cell-initiated programmed cell death. Furthermore, it has been shown that PARP1 can interact with, modify, and regulate epigenetic remodeling proteins such as chromatin insulator protein CTCF (CCCTC-binding factor) and DNMT1 (DNA methylation maintenance protein); thus, the right balance between PARylation and PAR degradation by PARG is crucial for the maintenance of DNA methylation patterns in normal cells [8-10]. Of note, years ago, specific enzymes in arthropods and bacterial toxins were shown to transfer an ADP-ribosyl moiety to double- and single-stranded DNA nucleobases in a reversible manner $[11,12]$. Later on, it has been demonstrated that mammalian PARP1, -2 , and -3 (having the ability to act as DNA break sensors) modify not only cellular proteins but also terminal phosphate residues at doublestrand DNA break (DSB) and single-strand DNA break (SSB) termini $[13,14]$. Recently, RNA also was identified as a target of reversible mono-ADP-ribosylation [15]. At present, the biological role of PARP-mediated ADP-ribosylation of DNA strand break termini remains unclear, but might be different from that of proteins. This review focuses on the interplays among DNA breaks, ADP-ribosylation, and DNA epigenetic signatures. We also discuss the putative role of ADP-ribosylated DNA breaks in DNA metabolism and in the recruitment of specific PAR-DNA or MAR-DNA adduct-guided factors. 


\section{PARPs at the center of stress response pathways}

Cellular stress responses are mediated by various sensors and effectors from multiple signaling pathways including phosphorylation, ubiquitylation, SUMOylation, methylation, acetylation, and ADP-ribosylation. PARylation and MARylation [poly- and mono(ADPribosyl)ation] catalyzed by PARPs alter the function of the modified proteins and provide a scaffold for the recruitment of other proteins, which in turn can also undergo ADP-ribosylation. The latter regulates a number of biological processes including the DNA damage response, chromatin reorganization, transcription, apoptosis, autophagy, mitosis, and cell metabolism and development (reviewed in [5,16-18]).

The family of PARPs, also known as diphtheria toxin-like ADP-ribosyl-transferases (ARTDs), includes 17 known members [19,20]. Highly divergent PARP homolog tRNA 2'phosphotransferase 1 (TRPT1) is sometimes referred to as the $18^{\text {th }}$ PARP family member [21]. According to their structures, PARPs can be subdivided into four subfamilies: DNA-dependent PARPs (PARP1, PARP2, and PARP3), tankyrases (PARP5a and PARP5b), CCCH (Cys-CysCys-His) zinc finger and WWE (Trp-Trp-Glu) domain-containing PARPs (PARP7, PARP12, PARP13.1, and PARP13.2), and macrodomain-containing PARPs (PARP9, PARP14, and PARP15). Although PARP13 is not yet shown to have a catalytic activity [4], most of PARPs have the function of transferring PAR or MAR moieties onto their target proteins [22], DNA $[13,14,23]$, or RNA termini [15]. PARPs play a role in a wide range of biological structures and processes, including DNA repair and maintenance of genomic stability, transcriptional regulation, centromere function, mitotic spindle formation, centrosomal function, the structure and function of vault particles, telomere dynamics, trafficking of endosomal vesicles, inflammation, apoptosis, and necrosis $[6,22,24]$. 
The founding member of the PARP family as well as the most ubiquitous and abundant PARP, PARP1 was the most studied. This $110 \mathrm{kDa}$ nuclear protein is composed of six domains essential for DNA binding, nuclear homing, automodification, protein-protein interactions, and catalytic activity. PARP1 is responsible for $80 \%$ to $90 \%$ of the PARylation activity in the cell [25]. Based on the structure-function relationship studies, PARP1 was initially characterized as a critical player in the DNA damage response and repair processes under stressful conditions. PARylation can lead to accelerated dissociation of modified proteins from DNA owing to the negative charge of the PARylated protein and steric hindrance. The best example of this dissociation is PARP1-mediated PARylation of histone $\mathrm{H} 1$ and PARP2-mediated PARylation of histone $\mathrm{H} 2 \mathrm{~B}$; these modifications cause the dissociation of these histones from DNA and eventually chromatin relaxation required for replication, transcription, DNA repair [2628]. Later on, the list of known biological functions of PARP1 has been expanded: regulation of chromatin structure, transcription, stress responses, and involvement in various physiological processes [29]. Moreover, the roles of PARP1 under normal physiological conditions have been further substantiated, e.g., the regulation of gene expression, RNA biology, and processes in cytoplasm. Recently, PARP1 has been identified as a sensor of unligated Okazaki fragments—during DNA replication in normal S phase cells-which facilitates their maturation [30]. The remaining ADP-ribosylation activity in the cell lacking PARP1 (in embryonic fibroblasts derived from PARP1 1 knockout mice) falls to other active PARP members, which may or may not share structural similarities or localization with PARP1 but certainly share a highly conserved catalytic (CD) domain (PARP signature). The latter consists of a helical regulatory domain (HD) and an ADP-ribosyl transferase domain (ART) responsible for the catalytic activity, present in PARP2 and PARP3.

PARP2 was discovered as the enzyme responsible for the basal PARylation activity in PARP1deficient cells [31] and accounts for $\sim 10 \%$ of the PARylation activity in the cell. Just as PARP1, PARP2 recognizes and binds a DSB or SSB. The binding of PARP2 to damaged DNA structures triggers its PARylation activity. PARP2 has partially redundant functions with PARP1 
that are essential for normal embryogenesis. Double-knockout Parp ${ }^{-/-}$Parp2 ${ }^{-/-}$mice show early embryonic mortality [32]. PARP2 has a function, independent of its PAR synthesis activity, which limits the accumulation of the resection barrier factor 53BP1 at DNA damage sites and directs DSBs toward resection-dependent repair pathways [33]. Aside from DNA repair, cell cycle regulation, and inflammation and metabolic regulation, PARP2 acts as a cofactor in transcription and can regulate the expression of 600 to 1,000 genes by facilitating transcription or via attraction of cofactors promoting chromatin compaction and the consequent inhibition of transcription [34-37].

PARP3 is related to PARP1 and PARP2 and its domain organization is similar to that of PARP2, but PARP3 catalyzes MARylation instead of PARylation [20]. Similar to PARP1 and PARP2, PARP3 is an important player in cell cycle regulation and DNA repair [38]. This PARP interacts with PARP1, DNA ligase III, Ku70/80, other nonhomologous end-joining (NHEJ) proteins and promotes processing DSBs in the canonical NHEJ pathway [39]. Other than its role on the DNA damage response and repair, PARP3 has also been reported to associate with Polycomb group proteins involved in transcriptional silencing and chromatin-remodeling $[40]$.

PARP4 (also called VPARP or ARTD4) is a component of the cytosolic ribonucleoprotein vault complex [24] and is also present in cytoplasmic clusters (vPARP rods) as well as in the nuclear matrix [5]. The conserved glutamate residue in PARP1 is replaced with isoleucine, leucine, or tyrosine in PARP4, which is associated with the absence of polymerase activity [41]. It was proposed that PARP4 may be involved in an antiviral response [42].

PARPs 5a and 5b (tankyrases) were initially identified as a part of a telomeric complex but are also located in the cytoplasm as peripheral membrane proteins localized at the Golgi complex and are associated with transport vesicles [5]. They are best known for their participation in mitosis and WNT signaling, but they also have functions in telomere and DNA damage repair [24]. Recently, a possible link between tankyrases and the DNA damage response has been proposed. On the one hand, tankyrases associate with DSBs to facilitate the recruitment of the 
CtIP-BRCA1 complex to damaged chromatin and to promote DNA end resection during homologous recombination (HR); on the other hand, tankyrases associate with DSBs to stimulate the recruitment of the BRCA1A complex (consisting of RAP80-BRCA1-BRCC36CCDC98) mediated by MERIT40 and activate the G2-M checkpoint for promoting DNA repair before mitosis [43].

PARP6 has been found to be involved in hippocampus neuronal development [24]. Moreover, it plays a role in cell cycle progression and has been associated with the progression of colorectal cancer [42]. Of note, the biological activity of PARP6 depends on its catalytic activity as well as its $\mathrm{N}$-terminal cysteine-rich domain [41].

Several PARPs (PARP7, PARP10, PARP12, and PARP13) are involved in the mechanisms of posttranscriptional regulation of mRNA; the latter process is mediated either by RNA-binding domains or by ADP-ribosylation of RNA-binding proteins [24]. PARP7, present in stress granules [5], is involved in antiviral responses, cytosolic RNA processing, and transcription [34]. PARP10 is a binding protein and an inhibitor of MYC [42] and has been implicated in the regulation of nuclear factor kappa B (NF-KB), GSK3B, and transcription [24]. PARP10 directly ADP-ribosylates NEMO. These events lead to the inhibition of nuclear localization of the p65 subunit of NF-KB and to subsequent attenuation of NF-KB-dependent gene expression [41]. PARP12 is a catalytically active cytosolic monoenzyme [43], which preferentially associates with the Golgi apparatus and regulates stress granule assembly, microRNA activity, and an antiviral response [42]. Intracellular expression of PARP12 increases upon stimulation by type Il interferons, thereby leading to increased NF-KB signaling, implicating PARP12 in cellular immune responses [41]. PARP13, also referred as ZAP (zinc finger antiviral protein), has been so far regarded as a catalytically inactive ART with the roles in the assembly of stress granules and regulation of microRNAs, with consequent implications in innate antiviral defense and cancer $[42,43]$.

PARP9 and PARP14 are believed to act on transcription, especially the transcription of genes required for macrophage activation [24]. PARP9 possesses a unique MARylating activity 
specifically targeting the ubiquitin peptides and participates in the DNA damage response, transcription in lymphocytes, and in antiviral response [42]. PARP14 has been implicated in multiple cellular functions such as survival of B cells, cell migration, assembly of stress granules, transcription during inflammation processes, the DNA damage response, and an antiviral response [42]. PARP14 regulates the class distribution, affinity repertoire, and recall capacity of antibody responses, which require efficient differentiation and interactions among B cells, T helper cells, and dendritic cells [41].

Concurrently with its nuclear pore localization, PARP11 modifies targets involved in the coordination of the nuclear envelope and organization of nuclear pores and nuclear envelope biology $[24,42]$. PARP15 is a centrosomal PARP involved in stress granule formation, an antiviral response, cytosolic RNA processing, and tumor formation $[41,42]$. PARP16 is located in the endoplasmic reticulum (ER) and regulates the unfolded protein response [24,42]. Cellular localization of other PARPs (PARP8 and PARP17) and their involvement in biological processes remain unknown.

Moreover, some PARP family members can interact with each other, e.g., PARP1 with PARP2 or PARP3 as well as tankyrase 1 with tankyrase 2 [27]. This type of heterodimers may occur in different subcellular compartments and act on different substrates, which monomeric PARPs could not otherwise target individually. This observation may highlight a new organizational order for PARPs that may greatly diversify their biological responses, via combinatorial interactions.

Excessive ADP-ribosylation can lead to the activation of cell death pathways, including parthanatos, a unique form of programmed cell death that occurs independently of caspases and is distinct from necrosis and apoptosis [44]. Due to its manifold role in cell survival, the protein PARylation process is finely regulated. PAR is rapidly degraded PARG, the main enzyme that specifically hydrolyses ribose-ribose bonds encoded by a single gene in mammals [7]. Disruption of the PARG gene in mice causes embryonic lethality, and studies of PARG-deficient cells have shown that accumulation of PARylated macromolecules is highly 
toxic to the cell $[45,46]$. Nevertheless, PARG has rather limited processivity on short PAR polymers and is unable to remove MARylation marks from proteins [47]. A complete reversal of MARylation is performed in human cells by amino acid-specific ADPr-acceptor hydrolases, such as macrodomain-containing proteins MacroD1 and MacroD2, terminal ADP-ribose protein glycohydrolase 1 (TARG1), and ADP-ribosylhydrolase (ARH) family members $A R H 1$ and $\mathrm{ARH} 3$ (reviewed in [48]).

\section{Protein acceptors for ADP-ribosylation}

Despite PARPs' different biological functions, over decades, little has been known about ADPr acceptors. Starting from the protein PARylation discovery, for ADP-ribosylated proteome analysis, researchers have applied chemical (high $\mathrm{pH}$, hydroxylamine) or enzymatic sensitive methods (based on ARH1, PARG, ARH3, SVP, or NudT16) to quickly release the ADPr groups from modified residues. Hayaishi's group provided one of the first mechanistic insights into PAR synthesis. They demonstrated that in the rat liver, ADPr binds to histone $\mathrm{H} 1$ through an ester linkage with either a $y$-carboxyl group of glutamic acid residue 2 or 14 or with an $\alpha$ carboxyl group of C-terminal lysine residue 213 [49]. Linker histones $\mathrm{H} 1$ and $\mathrm{H} 5$ are known to be primary targets for PARP1-catalyzed PARylation, whereas PARP2 and PARP3 preferentially ADP-ribosylate core histone H2B [50-52]. PARP3 preferentially adds a mono ADPr moiety on Glu2 of histone H2B upon DNA damage [51]. Until 2017, it had been generally thought that PARP-catalyzed auto-PARylation and ADP-ribosylation of other proteins occur predominantly on aspartates, glutamates, and lysines [53-55]. Nonetheless, conventional approaches have to overcome many limitations, such as the dynamic heterogeneous nature of protein ADP-ribosylation, low abundance, lability of some sites, and chemical or enzymatic resistance of other ADPr acceptor sites. The evolution of methods for the detection of MAR/PAR attachment sites has led to the use of mutagenesis assays as well as $\mathrm{NAD}^{+}$analogs, unbiased enrichment strategies, chemotherapeutic PARP inhibitors, advanced mass spectrometry (particularly based on electron-transfer higher-energy collisional dissociation), and quantitative proteomic techniques [56-59]. Investigators have uncovered modification of 
more than 7000 ADP-ribosylation sites across more than 2000 ADP-ribosylation target proteins covering over one-third of the nuclear proteome under genotoxic stress conditions [59]. Upon DNA damage, serine (Ser) becomes the major ( $\approx 90 \%)$ ADPr acceptor residue with the most easily identifiable signals related to the modification of histone proteins as well as PARP automodification $[57,59]$. Histones are MARylated selectively on serine residues of histone $\mathrm{H} 3$ (Ser10 and Ser28) and Ser6 of H2B unless the neighboring lysine residues are acetylated $[57,60]$. Notably, Ser ADP-ribosylation sites strongly overlap with known kinase-regulated sites (Aurora B and others) [59]. ADP-ribosylation and phosphorylation of these serine residues are considered mutually exclusive [60], suggesting a complex interplay between histone marks. The major hydrolase responsible for the reversal of the Ser-ADPr modification is ARH3 [61,62]. ARH3-deficient cells show a dramatic increase of PAR content in response to hydrogen peroxide exposure with induction of an AIF release from mitochondria and parthanatos $[62,63]$. Moreover, the specificity of ADP-ribosylation is regulated by different factors. HPF1 (histone PARylation factor 1) interacts with PARP1 and PARP2 and guides the ADP-ribosylation of PARP1 and high-mobility group proteins through a serine residue [56]. In HPF1's absence, acidic residues (Asp and Glu) become the main target sites for ADPr in proteins. Hundreds of ADP-ribosylation sites are also located on histidine, arginine, lysine, cysteine, and tyrosine residues $[59,60,64]$. It is still possible that further development of proteomic tools will allow researchers to detect new types of modifications, such as an acid-labile ADPr adduct of phosphoserine residues. This chimeric modification was noted in histones from the rat liver more than 40 years ago [65], but the enzymes responsible for its formation are still unknown. The diversity of ADPr substrate amino acids has revealed the importance of this PTM in cell signaling and survival and thus the necessity of its regulation.

\section{Readers of ADP-ribosylated targets}

ADP-ribosylation is a PTM of proteins: it induces the recruitment of the protein (such as TET [66], TP53 [67], NF-kB [68]) or modulates its activity by covalent or noncovalent binding. Aside from protein modification, ADP-ribosylation is also involved in signaling as well as protein- 
protein or protein-DNA interactions [69]. PARylation as a PTM directly regulates many cellular pathways such as transcription, chromatin modification, and DNA damage and oxidative-stress signaling. Proteins may have a PAR- or MAR-recognizing domains (Figure 2) that bind to PAR polymers or MAR moieties [29]. Depending on the nature of recognition, different proteins have different motifs. For instance, a PAR-binding motif (PBM) is believed to engage in an electrostatic interaction with negatively charged PAR chains $[69,70]$, whereas a PAR-binding zinc finger (PBZ) recognizes two consecutive ADPr moieties although some can also recognize only one ADPr of a PAR chain [71-73]. Similarly to PBZ, WWE requires two consecutive ADPr units for its successful binding; hence, it interacts with iso-ADPr formed by both ADPr units [74]. FHA (fork head-associated) and BRCT (BRCA1 C-terminal) are protein domains that are mostly known to interact with phosphorylated peptides but also have affinity for PAR chains [75]. The latter interaction seems to be similar to that of WWE domain or PBM, respectively. Another class of ADPr-recognizing domains is macrodomains. Unlike other domains, macrodomains interact with mono-ADPr or the terminal ADPr of PAR chains in the case of $\mathrm{H} 2 \mathrm{~A} 1.1$ [76]. There are also RNA- and DNA-binding motifs that unexpectedly recognize PAR ADPr moieties [77].

\section{The PBM}

The consensus sequence of a PBM is ([HKR]-X-X-[AIQVY]-[KR]-[KR]-[AILV]-[FILPV]), i.e., approximately 20 residues. The positively-charged-amino acid content of a PBM allows for an electrostatic interaction with highly negatively charged PAR polymers. PBMs have been detected in more than 800 proteins in silico, and $>500$ hits have been obtained in proteomic analysis $[69,70]$. PBMs are often found in many DNA damage response proteins and other proteins that are included in the ADPriboDB database of ADP-ribosylated proteins [78], suggesting that PAR binding promotes PARylation. For example, tumor protein p53 (p53, TP53) can bind to PAR polymers both in a covalent and in a noncovalent manner. TP53 contains multiple PBMs. Hence, Fishbach et al. suggest that TP53 gets covalently PARylated upon a noncovalent interaction between a PBM located in a C-terminal domain of TP53 and 
PARylated PARP1 [67]. They demonstrated that noncovalent PAR binding diminishes the sequence-independent DNA-binding capacity of TP53. Nevertheless, simply having a PBM seems to be insufficient for PAR binding. For instance, the entire BRCT domain of XRCC1rather than a short PBM-is required for its affinity for PAR [75].

\section{$\underline{T h e} P B Z$}

The PBZ is a $\mathrm{C} 2 \mathrm{H} 2$ zinc finger domain consisting of approximately 30 amino acid residues. The PBZ domain has a consensus sequence of $[K / R]-X-X-C-X-[F / Y]-G-X-X-C-X-[K / R]-[K / R]-$ $\mathrm{X}-\mathrm{X}-\mathrm{X}-\mathrm{X}-\mathrm{H}-\mathrm{X}-\mathrm{X}-\mathrm{X}-[\mathrm{F} / \mathrm{Y}]-\mathrm{X}-\mathrm{H}$ and so far has been discovered in three proteins: APLF (aprataxin and PNK-like factor), CHFR (checkpoint with forkhead-associated and ring domain), and CTCF [77]. Unlike CHFR, APLF contains two PBZ domains. Accordingly, one of the two PBZ domains identified in the APLF protein interacts with two consecutive ADPr units, whereas the second PBZ domain is thought to bind to the $3^{\text {rd }}$ ADPr unit likely on a branched PAR polymer or terminal poly-ADPr. The PAR recognition by APLF induces its histone chaperone activity for the release of histones $\mathrm{H} 3$ and $\mathrm{H} 4$ and chromatin relaxation $[79,80]$.

\section{Macrodomains}

Macrodomains are mono-ADPr-recognizing domains [76]. One of the well-studied macrodomains is histone variant macroH2A1.1. In addition to MAR, macroH2A1.1 can recognize PAR polymers via their terminal ADPr unit. MacroH2A1.1 participates in metabolic regulation and energy production by inhibiting PARP1 activity and decreasing its nuclear NAD+ consumption [81]. MacroH2A1.1-PARP1 interaction is also involved in gene regulation, for instance, in response to heat shock stress and during expression regulation of senescenceassociated secretory phenotype genes or genes participating in adipocyte differentiation and metabolic regulation during muscle differentiation [82]. Another macrodomain-dependent chromatin-remodeling factor is ALC1. This is an inactive ATPase and one of the chromatin remodelers that activates upon DNA damage. During DSB repair, MacroH2A1.1 [83] and ALC1 [84] take part in chromatin remodeling in a macrodomain-dependent manner. PARP family members PARP9, PARP14, and PARP15 have both the MARylation activity and a 
macrodomain interacting with MAR $[76,85,86]$. PARG, TARG1, and MACROD1-3 ADPrhydrolases also contain macrodomains [87].

\section{The WWE domain}

This domain contains two conserved tryptophans and a glutamic acid residue, hence its name, and in total is approximately $80-100$ residues long $[88,89]$. It recognizes iso-ADPr moieties between two consecutive ADPr units. The WWE domain is reported to be present mostly in E3 ubiquitin-protein ligases (RNF146, DELTEX1, DELTEX2, DELTEX4, and HUWE1) and in two PARPs (PARP11 and PARP14) [74].

\section{$\underline{\text { FHA and BRCT domains }}$}

These domains play a huge part in cellular responses to DNA damage by recognizing phosphorylated peptides $[90,91]$. It has also been discovered that FHA and BRCT domains can recognize PAR polymers. Similarly to the WWE domain, the FHA domain binds iso-ADPr of PAR chains by recognizing the two phosphate groups on ADPr moieties, whereas the BRCT domain directly recognizes ADPr of a PAR chain [75]. The latter phenomenon is possibly due to the phosphate groups on ADPr, which mimics the phosphorylated serine residue recognized by the BRCT domain [92]. ADPr recognition by an FHA or BRCT domain facilitates rapid recruitment of DNA damage response proteins: PNKP and aprataxin by the FHA domain and ligase IV, XRCC1, and the BRCA1-BARD1 complex by the BRCT domain [75,92-94].

\section{$\underline{R N A-\text { and DNA-binding motifs (RRM, SR repeat- and KR-rich motif, OB fold, PIN domain, and }}$}

\section{$\underline{\text { GAR domain) }}$}

Of note, RNA- and DNA-binding motifs can also bind to PAR. Although this is not very surprising because PAR chains have a structure similar to that of oligonucleotides. NONO, an RNA-binding protein, is believed to increase survival during DSB repair although its function is not yet clear; its recruitment is PARP1 dependent. RRM (RNA recognition motif) of NONO recognizes PAR, thereby facilitating the recruitment of NONO to a DNA damage site [95]. 
It has been shown that splice factors ASF/SF2, SF3A1, SF3B1, and SF3B2 can recognize PAR chains via their SR (serine/arginine) repeats [96,97]. PAR binding to splicing factor ASF/SF2 inhibits its phosphorylation by TOPI (DNA topoisomerase I) and activity [96], indicating the involvement of PARPs and PAR chains in RNA stability and metabolism [98]. In a similar context, upon heat shock, KR (lysine/arginine)-rich repeats of the Drosophila Mi-2 protein bind PAR chains thus leading to Mi-2 recruitment to heat shock-responsive genes [99].

Oligonucleotide/oligosaccharide-binding fold (OB fold) is an SsDNA- and RNA-binding motif. Just as WWE and FHA domains, the OB fold of human ssDNA-binding protein 1 (hSSB1) recognizes iso-ADPr of PAR chains in addition to its ssDNA-binding ability [100].

Proteins with PIN (PilT N terminus) domains are mostly nucleases cleaving ssDNA or ssRNA [101]. In particular, during DNA damage repair, the PIN domain of exonuclease 1 (EXO1) was found to recognize DNA damage-induced PARs, and this event is rather sufficient for its recruitment to the DNA damage site [102].

GAR (or RG/RGG box) is another PAR-binding domain and consists of a sequence enriched in arginine and glycine. There are several RNA-binding proteins with GAR domains known to recognize PAR chains during DNA damage responses, e.g., FUS/TLS, EWS/EWSR1, TAF15, and CIRBP $[77,103]$.

\section{Reversible ADP-ribosylation of DNA and RNA}

The first evidence of DNA ADP-ribosylation was obtained 20 years ago. Watanabe's group demonstrated that a cabbage butterfly toxin, pierisin, induces apoptosis via irreversible MARylation of a guanine base in DNA [104,105]. Later, other examples of DNA MARylation have been demonstrated for different families of toxins: guanine MARylation by CARP-1 from shellfish [11] and by scabin from Streptomyces scabies [106] as well as thymine MARylation by DarT from bacterial toxin-antitoxin system DarTG [12]. 
Recently, in vitro studies in our laboratory have uncovered that mammalian DNA-dependent PARPs catalyze reversible modification of DNA via ADP-ribosylation of terminal phosphates at DNA strand breaks [13]. This finding provides novel molecular insights into PARPs' functions in mammalian cells. Taking into account an unsolved challenge (how to distinguish ADPr adducts on proteins and DNA in the cell), DNA ADP-ribosylation studies have been focused on in vitro approaches to gain knowledge about the mechanisms and specific requirements for this unusual substrate specificity of PARPs. It has been found that PARP1 preferentially PARylates DSBs containing 5'- and 3'-terminal phosphates in gapped recessed DNA duplexes, whereas PARP2 and PARP3 preferentially act on 5'-terminal phosphates at DSB and SSB termini of DNA containing multiple proximal breaks $[13,14,23]$. Similarly to protein modification, PARP3 produces a MAR not PAR adduct on DNA substrates, in contrast to PARP1 and PARP2 [14,23]. In addition to phosphate groups, PARP1 can PARylate 2'-OH groups of 3'deoxynucleotide and ribonucleotides incorporated at the $3^{\prime}$ terminus of oligodeoxyribonucleotides [13]. A recent study by Zarkovic G. et al. revealed ADP-ribosylation of $\sim 3 \mathrm{~kb}$ plasmid-based DNA constructs, thus indicating DNA size limitlessness of PARPmediated modifications of DNA break termini [14]. Moreover, PARP2 and PARP3 switch their substrate preference to DNA from protein when acting upon certain configuration of closely spaced DNA strand breaks, preferentially ADP-ribosylating DNA rather than catalyzing autoADP-ribosylation. Effectiveness of PARP3- and PARP2-catalyzed DNA ADP-ribosylation depends on the orientation and a distance between DNA strand breaks in a single DNA molecule [14]. According to a proposed mechanistic model, binding of a PARP to one DNA break activates the CAT domain, which in turn targets and ADP-ribosylates an acceptor group at the second breakage site of the same DNA molecule $[13,14]$. This process necessitates the presence of at least two DNA strand breaks separated by a distance from 1 to 2 helix turns [14]. In a DNA-bound PARP complex, this distance determines the accessibility of the DNA acceptor groups for the activated CAT domain directing ADP-ribosylation to a 5'- or 3'-terminal phosphate. At present, little is known about the mechanisms governing substrate interaction and specificity of PARP1, which accounts for most of cellular PARylation activity. Moreover, it 
remains unclear of how can PARPs adopt the conformation thatpredisposes to DNA ADPribosylation activity. According to existing structural data on PARP1 and PARP2 bound to DNA breaks, the PARP's DNA-binding domain is far from its CAT domain, which is not oriented along the DNA helix $[35,107,108]$. Nevertheless, broad substrate specificity in trans, including also auto-modification of different amino acid residues in cis, and the multidomain structure of PARPs imply high flexibility of the CAT domain position in DNA-PARP complexes. Therefore, there may be some unexplored abilities to target substrates including formation of oligomeric protein complexes on DNA.

Effective DNA-PAR/MARylation occurs on DNA substrates that mimic intermediate products occurring in various DNA excision repair pathways such as base excision repair (BER), nucleotide excision repair (NER), mismatch repair (MMR), HR, and NHEJ. For example, DNA strand break acceptor sites containing 5'-phosphates can be generated by the action of various DNA exo- and endonucleases, tyrosyl-DNA phosphodiesterase 2 (TDP2), and dRP (5'deoxyribose phosphate) lyase activity of bifunctional DNA polymerases, whereas 3 '-terminal phosphates are produced by certain bifunctional DNA glycosylases, TDP1 and MRE11 [109,110]. DNA duplexes containing a DSB and a proximal SSB can form in HR and NHEJ repair pathways. It has been reported that a stably blocked replication fork can switch the endonuclease activity of MRN-CtIP complex on and produces an internal nick located $\sim 20 \mathrm{nt}$ downstream of 5'-termini of a DSB [111], thus ensuring proximity of activating and acceptor sites required for DNA ADP-ribosylation activity of PARPs.

At present, the physiological relevance of PARP-dependent DNA ADP-ribosylation is a debated issue. Nevertheless, a dramatic substrate switch of PARPs observed in vitro assays, the highly efficient PARP1-catalyzed DNA PARylation in human cell-free extracts, and the presence of a PAR signal in purified genomic DNA after genotoxic treatment provide the strong albeit indirect evidence of the presence of PAR-DNA adducts in live cells [14,112]. Furthermore, it has been shown that 1 nt gapped DNA containing a MARylated 5'-phosphate residue is recognized as a 5'-adenylated DNA substrate by DNA ligase I or Illa or by other 
DNA ligases and ligated in the absence of ATP, resulting in the sealed unbroken doublestranded DNA with an aberrant abasic (AP) site-like residue [112]. Such residue can be processed further by apurinic/apyrimidinic endonuclease 1 (APE1) in BER pathway [112]. In line with these results, it has been proposed that PARP2 and PARP3 are involved in the final ligation step of NHEJ, judging by the finding that 5'-phosphorylated nicks are especially efficient activators of the auto-ADP-ribosylation activity of PARP2 and PARP3 but not that of PARP1 [36]. We can hypothesize that DNA ADP-ribosylation can promote retention of the DSB ends either until a complete repair complex is formed or until the ATP concentration required for DNA ligation is restored. Similarly, in case of SSB repair, PARP-mediated ADP-ribosylation can promote the ligation of a gap without polymerase synthesis and ATP. Of note, extensive PARP-mediated PAR synthesis leads to inhibition of hexokinase 1 activity, blockage of glycolysis, and ATP loss [113]. Thus, one of the functions of DNA ADP-ribosylation can be the patching of DNA breaks during bioenergetic collapse avoiding formation or degradation of toxic DSBs.

Recent advances in RNA biology took the phenomenon of ADP-ribosylation to another level. Studies by Shuman's group have revealed that PARP-like tRNA splicing enzymes Tpt1 (KptA) from bacteria and fungi can ADP-ribosylate RNA and DNA at 5'-monophosphate termini [114,115]. Further studies by Ahel's laboratory have shown that Tpt1 homologs in higher organisms TRPT1 (PARP18) as well as human PARP10, PARP11, and PARP15 can MARylate phosphorylated ends of RNA [15]. This 5'-phospho-ADPr modification or "capping" of RNA termini may protect RNA substrates from degradation or dephosphorylation and mediate ADP-ribosylation signaling via recruitment of specific cellular factors. Overall, these RNA related studies provide additional evidence that the phenomenon of ADP-ribosylation of nucleic acids at terminal phosphates is more widespread than previously thought.

ADPr removal from DNA and RNA termini. ADP-ribosylation of DNA and RNA termini is a fully reversible process. We have demonstrated that PARG efficiently restores native DNA structure 
by hydrolyzing PAR-DNA or MAR-DNA adducts generated by PARP1, PARP2, or PARP3 $[13,14]$. Moreover, recently, Ahel's laboratory demonstrated that the MAR moiety that is covalently attached to oligonucleotide termini can also be removed by other cellular hydrolases, such as MACROD1, MACROD2, TARG1, and ARH3, though with much lower efficacy $[23,116]$. We believe that the half-life of DNA-PAR or DNA-MAR adducts is similar to that of PARylated proteins and may depend on the recruitment of PARG to the sites of ADPribosylation. In the absence of PARG, which is the major glycohydrolase in the nucleus, ADPribosylated DNA strand break termini would result in persistent DNA damage and is expected to be highly genotoxic as compared to the PARylated proteins: mainly PARPs and histones. Similarly, hydrolases PARG, TARG1, ARH3, and MACROD1 and -2 can restore intact RNA structure after ADP-ribosylation of a 5'-terminal phosphate [15]. The broad substrate specificity of glycohydrolases toward ADP-ribosylated DNA and RNA can be explained by the acid lability of the phosphodiester bond between ADPr and terminal phosphates in nucleic acids, in contrast to the bond between amino acids and ADPr in protein target [14]. Noteworthy, the replacement of a phosphate acceptor group with a thiophosphate residue has little impact on its ADP-ribosylation but makes MAR-DNA adducts resistant to PARG hydrolysis [14].

\section{DNA damage-induced DNA demethylation, ADP-ribosylation, and cell differentiation}

DNA damage response and repair proteins play a crucial role in genomic integrity. In addition, these proteins have important functions in gene expression, in particular during organism development and stem cell maintenance and differentiation. For instance, programmed DNA damage and repair are important in the immune response for B- and T-cell development and for generation of the diversity of antigen receptors [117]. In the adaptive immune system, not only DNA repair proteins but also other cell cycle regulators and checkpoint proteins play important roles. They function as regulators of proliferation, of introduction of diversity, and cell cycle arrest during $\mathrm{V}(\mathrm{D}) \mathrm{J}$ recombination and class switch recombination (CSR). Classic NHEJ 
is the major pathway repairing the RAG1/RAG2-induced DSBs during $V(D) J$ recombination, whereas in mature B cells, alternative NHEJ and other repair mechanisms such as BER also participate to repair the activation-induced cytidine deaminase (AID)-induced DNA lesions during CSR and somatic hypermutation [118]. In addition to the generation of antigen diversity, during B- and T-cell development, programmed DNA damage is a trigger for the expression of many genes including genes related to cell survival, proliferation, and development [119]. Deamination by AID occurs at the GC-rich transcriptional start sites of heavy-chain and lightchain genes where cytidine is converted into uracil. Uracil-N-glycosylase (UNG), BER, and MMR proteins detect the uracil residues in U.G mispairs. Thereafter, the nick will be introduced into DNA, and subsequent repair of the DNA lesion may lead to deletion, transition, and transversional mutations [120]. Alternatively, the repair of deaminated bases via the nickinitiated long-patch DNA excision-resynthesis mechanism during long-patch BER [121,122], NER [123], and noncanonical MMR [124] leads to replacement of neighboring 5-methylcytidine nucleotides by unmodified nucleotides. Thus, locus-specific AID targeting in transgenic mice has been reported to induce local processive DNA demethylation even $\sim 1 \mathrm{~kb}$ beyond its target motif [122]. Activation and regulation of AID are not yet well characterized, although CSR is initiated by AID-induced DNA lesions at least after three cell cycles [120], and AID is more stable in the G1 phase and is regulated by the cell cycle [125]. Accordingly, replicationdependent types of DNA damage may be the prior signal for the initiation of CSR and upregulation of $A I D$ expression regulated by NF-KB signaling $[126,127]$. AID is active on singlestranded DNA (ssDNA), indicating the presence of a secondary structure of DNA (like R-loops) during the initiation of CSR and somatic hypermutation [128]. Indeed, it has been suggested that AID recognizes G4 (quadruplex) DNA structures with at least a 5 nt ssDNA overhang prior to CSR [129].

There are multiple types of stem cells, which exploit endogenous types of DNA damage to regulate their differentiation. Immortalized myoblasts, which follow the fate similar to that of activated skeletal muscle stem cells, need BER factors to differentiate successfully [130]. A 
while ago, endogenous DNA damage was observed immediately prior to myotube fusion $[131,132]$. These DNA lesions have been predicted to be SSBs or DNA nicks, which are some of the major causes of PARP activation [133]. Consistently with these data, Farzaneh et al. mentioned the need for PARP activity during terminal differentiation of myoblasts [131]. Later, it was also discovered that these types of DNA damage are induced by caspase-activated DNase (CAD), which in the end leads to changes in gene expression patterns, for instance, upregulation of p21, a cyclin/cyclin-dependent kinase (CDK) inhibitor protein inducing cell cycle arrest [134]. Indeed, these types of CAD-dependent DNA damage may be one of the reasons because they trigger the changes in the DNA methylation pattern of differentiating myoblasts, and these alterations eventually lead to the upregulation of myogenic factors needed for multinucleated myotube fusion [135].

ADP-ribosylation-dependent chromatin remodeling is critical for initiating the expression of genes. For example, neural activation by stimulation of immediate-early-gene expression requires a release of linker histone $\mathrm{H} 1$. Accordingly, Azad et al. have shown that a release of $\mathrm{H} 1$ from the promoter of an immediate early gene requires ADP-ribosylation by PARP1 and phosphorylation of the histone [136]. PARylation_dependent $\mathrm{H} 1$ disposition has also been observed in hormone-regulated genes [137]. A growing number of studies have revealed that PARP1 regulates gene expression through PARylation of histone methyltransferases and demethylases $[66,138]$. This in turn changes the histone $\mathrm{H} 3$ and $\mathrm{H} 4$ acetylation and methylation statuses and subsequently strongly alters the regulation of gene expression patterns independently of histone ADP-ribosylation, pointing to the critical role of chromatin modifying factors in transcription regulation [28]. Notably, PARyation of epigenetic regulators at DNA damage sites is very important to maintain the histone mark balance to ensure correct spatial and temporal coordination of DNA repair. In this context, ADP-ribosylation may be linked to the repair of DNA damage and chromatin remodeling; however, this mechanism may not be enough to explain the epigenetic regulation of genes responsible for the fate of the cells undergoing either B-cell or T-cell development and during myogenic cell differentiation in the 
absence of ADP-ribosylation. Accordingly, ADP-ribosylation may contribute to the signaling cascade during epigenetic regulation since the methylation patterns of the cells are changing at the target sites in related genes and not globally. One of the vivid examples of this phenomenon is the concentration of programmed DNA damage at the promoter site of the $p 21$ gene during myogenic differentiation [134].

\section{Active DNA demethylation as a source of programmed DNA breaks}

Dynamic DNA methylation is one of the major epigenetic regulation mechanisms. DNMTs (DNA methyltransferase enzymes) transfer a methyl group onto the $5^{\prime}$ position of cytosine. Methylated cytosine is a signature of repressed gene expression. DNA methylation regulates tissue-specific gene expression, genomic imprinting, and X-chromosome inactivation [139]. Additionally, the majority of gene promoters are located in the proximity of $\mathrm{CpG}$ islands, which are CG repeat-rich sequences. Unmethylated and methylated CpG islands are associated with actively transcribed and inactive genes, respectively [140]. Embryonic stem cells have approximately $4 \%$ of the $\mathrm{CpG}$ islands methylated [141], and this figure increases to $70-80 \%$ in somatic cells [142]. This difference can be related to the pluripotency of stem cells or the differentiated or specialized state of somatic cells. To switch pluripotency off, heterochromatinization takes place, followed by DNA methylation. Histones $\mathrm{H} 3$ and $\mathrm{H} 4$ are methylated. For instance, H3K9 residues get trimethylated by G9a, a histone methyltransferase, and are deacetylated by histone deacetylases. This event is followed by the recruitment and activity of DNA methyltransferases DNMT3 and DNMT3B [143].

DNA methylation can be modulated either for the developmental, differentiated gene expression or to avoid the hypermethylation of $\mathrm{CpG}$ islands, which are maintained under hypomethylation state [144]. In vertebrates, the most studied proteins involved in DNA demethylation are activation-induced deaminase/apolipoprotein B mRNA-editing catalytic polypeptide-like (AID/APOBEC) family, which are cytidine deaminases, and the ten-eleven translocation (TET) family of proteins [145]. It has been suggested that AID-catalyzed 
deamination of 5-methylcytosine $(5 \mathrm{mC})$ to thymine results in the formation of the mismatched base pair G•T, which is repaired by methyl-CpG-binding domain protein 4 (MBD4)-initiated BER [146]. It should be noted that deamination of $5 \mathrm{mC}$ may be carried out not only by proteins of the AID/APOBEC family but also by DNA methyltransferases DNMT3A and DNMT3B in the absence of the methyl donor S-adenosylmethionine [147]. The participation of AID/APOBEC families has been extensively reviewed by Rebhandl et al.; the authors stated that AID/APOBEC takes part in many different cellular processes mostly by introducing a mutation. These enzymes play a role in B- and T-cell development by mutating immunoglobulin heavychain variable genes $(\mathrm{IgV})$, thereby increasing the diversity of generated antibodies. The APOBEC family also participates in immune defense by targeting and mutating viral DNA [148].

TET enzymes belong to the family of 2-oxoglutarate-dependent dioxygenases. There are three members of the TET family in vertebrates: TET1, TET2, and TET3. They are all responsible for the demethylation of $5 \mathrm{mC}$ in DNA by oxidizing it into 5-hydroxymethyl-cytosine $(5 \mathrm{hmC})$, which can be followed by oxidation into 5 -formyl-cytosine or 5-carboxyl-cytosine (5caC) $[149,150]$. It is believed that each form of oxidized cytosine has specific readers that can bind it, possibly to regulate the expression of genes. During active DNA demethylation, 5formyl-cytosine and $5 \mathrm{caC}$ residues are removed from DNA by thymine-DNA glycosylase (TDG) in the BER pathway $[149,151]$. An alternative murine demethylation pathway involving $5 \mathrm{mC}$ oxidation prior to deamination has been proposed, based on a complex of GADD45A, AID, and TDG detected and the finding that SMUG1, MBD4, or TDG has a glycosylase activity on 5-hydroxymethyl-uracil [145,152].

DNA demethylation of the paternal genome in murine primordial germ cells is mechanistically linked to the emergence of SSBs, high levels of PARP1 expression, and activation of the BER pathway, accompanied by the appearance of $\mathrm{YH} 2 \mathrm{~A} . \mathrm{X}$ foci and nuclear PARylation $[153,154]$. Suppression of BER by PARP1- and APE1-specific small-molecule inhibitors increases methylation of the paternal genome both globally and in LINE1 elements [154]. Taken together, 
these data indicate that DNA breaks and activation of PARPs are important for active DNA demethylation.

\section{Interplay between PARylation and DNA methylation}

PARPs-catalyzed PARylation performs diverse and important functions in the regulation of both DNA methylation and demethylation. Nucleosome-bound PARP1 is enriched in chromatin domains showing lower $5 \mathrm{mC}$ content within $1 \mathrm{~kb}$ from the transcription start sites of highly expressed genes [155,156]. For example, Dnmt1, p16, $\alpha$-SMA (smooth muscle actin alpha), pluripotency-related genes, NF-KB-dependent genes, peroxisome proliferator activated receptor y (PPARY)-dependent genes, and other genes are regulated by PAR moieties and PARP1 located at the promoter site (for more detailed review see Ciccarone et al. [66]). DNMT1 plays an important part in DNA methylation of newly synthesized hemimethylated DNA during replication $[157,158]$. Zampieri and coauthors demonstrated that PARP1 is colocalized with PAR specifically at one out of the five inferred Dnmt1 promoter regions [159]. AutoPARylated PARP1 and PAR polymers interact with both CTCF and DNMT1, thereby preventing their access to DNA and methylation of cytosines $[9,160]$. DNMT1 contains two PAR-binding domains that render higher affinity of the methyltransferase to PAR polymers than to DNA [159]. Accordingly, overexpression of hydrolase PARG causes increased methylation of the Dnmt1 promoter and repression of Dnmt1 expression [159]. The existence of an additional layer of DNMT1 expression control should be noted: through PARP1-catalyzed PARylation of the UHRF1 factor, which mediates ubiquitination of DNMT1, to ensure its timely regulated abundance in S and G2 phases [161]. Competitive PARP inhibition leads to global genomic-DNA hypermethylation mainly concentrated in CGI (CpG island) regions in vivo, whereas hyperactivation of PARP1 leads to hypomethylation [159]. In the absence of ADPribosylation, a particular gene could also be differently affected as hypermethylated at the CGIs of the promoter site while hypomethylated within the gene body [156]. Finally, PARP1mediated PARylation of methyl CpG-binding domain protein 2 (MeCP2) impairs its ability to bind $5 \mathrm{mCpG}$ sites and reorganize heterochromatin [162]. Overall, these observations suggest 
that the dynamic PARylation of target proteins is involved in the crosstalk between PARP1 and DNA methylation.

Nevertheless, the origin of PARP1 activation on those promoter regions remains poorly understood. Based on in vitro data, it has been proposed that CTCF directly interacts with PARP1 and induces PARP1 automodification in a DNA-independent manner [9]. Nevertheless, no solid evidence available that this mechanism is responsible for the observed PAR synthesis in the cell. In vitro data show that the level of PARP1 activity was $\sim 10$-fold higher in the presence of both activated DNA and CTCF as compared to just DNA and CTCF alone [9]. In this regard, the combined action of both DNA breaks and CTCF seems preferable for the induction of PARP1 automodification during PARP1-mediated regulation of gene expression at certain promoter sites in the genome. Moreover, several studies indicate that even though CTCF plays certain roles in the regulation of gene expression, DNMT1 [159] and under certain circumstances $p 16$ can still be expressed in the absence of CTCF but not that of PAR polymers [163]. In the context of genotoxic stress-induced enzymatic modifications of DNA, CTCF is actually recruited to the DNA damage site once there is PAR in the proximity of the lesion. CTCF has 11 zinc finger domains that can bind to DNA and among them zinc finger 4-6 motifs have been reported to recognize and bind PAR chains, which are structurally similar to ssDNA [164]. CTCF can also be PARylated by the PARP proteins. This PARylation seems to be cellcycle-dependent; proliferating cells hardly contain any ADP-ribosylated CTCF, whereas the cells under cell cycle arrest contain a large amount of modified CTCF. This PARylation also correlates with upregulation of many genes responsible for cell cycle arrest, differentiation, and development [165]. It is noteworthy that Klenova and colleagues have provided evidence that CTCF dissociates from majority of sites on chromatin after PARylation [165]. This idea also supports the notion of CTCF binding to ADPr motifs instead of intact DNA [164].

Moreover, the physical and functional interplays among CTCF, DNMT1, and PARP1 also involve TET proteins. On the one hand, CTCF interacts with and recruits TET proteins to genomic DNA, thus promoting oxidation of $5 \mathrm{mC}$ [166]; on the other hand, TET-catalyzed 
formation of $5 \mathrm{hmC}$ and especially $5 \mathrm{caC}$ strengthens CTCF's association with DNA $[167,168]$. TET expression is positively regulated by the PARylation activity of PARP1, which leads to DNA demethylation [169]. Additionally, covalently PARylated TET enzymes convert 5mC into its oxidized forms more efficiently, although as negative feedback, noncovalent binding of PAR to a TET protein represses its activity [66]. Accordingly, a noncovalent PAR-binding motif has been identified in the catalytic domain of TET1 [170]. It should be emphasized here that $5 \mathrm{caC}$ residues can serve as a potential source of SSB and subsequent PARP activation, when they are processed by TDG-dependent BER. Alternatively, TET1 can also activate PARP1 in vitro in the absence of nicked DNA [170], making their interactions even more complex. Accordingly, TET1-dependent activation of PARP1 would lead to covalent PARylation of TET1 and induction of its hydroxylase activity, which can be blocked at some point by non covalent interaction of TET1 with PAR. Nevertheless, inactive TET1-PAR complex still can bind DNA, block the access to DNMT1, and act as an anchor for the transcription factors via PAR interaction [170]. Moreover, it was shown that TET1 is recruited by PARP1-dependent PARylation at the PPAR response elements and promotes the local production of $5 \mathrm{hmC}$ during adipocyte differentiation [171].

\section{Crosstalk of transcription, DNA breaks, PARylation, and epigenetic regulation}

Regardless of exogenous or endogenous DNA-damaging agents, during DNA transcription and replication, different regions of genomic DNA show increased susceptibility to DNA breakage owing to multiple factors such as noncanonical DNA secondary structures (G-quadruplexes, hairpins, or R-loops) or a chromatin context (chromosomal fragile sites) (reviewed in $[172,173])$. Secondary structures of DNA increase the risk of DNA breaks: either targeted ones such as G4 structures recognized by AID during B-cell development or off-targeted G4s in active gene regions [129]. Another vivid example of transcription-associated DNA damage is the damage due to formation of R-loops: a naturally occurring reannealing of the nascent RNA 
transcript with the template DNA strand, with the accompanying displacement of the opposite ssDNA strand. Unscheduled formation of R-loops is associated with DNA breaks, replication fork stalling, and transcription blockage [174]. Notably, aside from transcription pausing, Rloops are also observed in unmethylated CGI sequences in the proximal promoter regions during development, possibly regulating transcription activation and restricting DNA methylation by DNMT3B1 [175]. Formation of R-loops is favored by negative supercoiling behind RNA polymerase II and by a specific sequence context (reviewed in [176]). TOP1 counteracts both positive and negative DNA supercoiling during transcription by introducing SSBs accompanied with the formation of transient TOP1 cleavage complexes (TOP1ccs) at their 3 ' termini [177]; this event leads to a decrease in the formation of DNA:RNA hybrids [178]. TOP1ccs are readily "trapped" on chromatin and become irreversible covalent adducts, which, if not repaired, can lead to transcription and replication blockage and formation of SSBs and DSBs. It has been reported that cleavage of the ssDNA strand of R-loops by endonucleases, including XPF, XPG, and FEN1, results in TOP1cc-induced DSB production during transcription in nonreplicating cells [179].

Nevertheless, the DNA damage in promoter and enhancer regions upstream of transcription start sites can stimulate transcription instead of blocking it by switching on DNA damage response pathways including PAR signaling (Figure 3). Indeed, activation of estrogenresponsive gene transcription of pS2 is dependent on the $\beta$ isoform of DNA topoisomerase II (TOP2 $\beta$ )-induced DSBs in the promoter region [180]. This phenomenon has also been observed in androgen receptor, retinoic acid receptor, and activator protein 1-dependent types of gene transcription [180]. In general, TOP2 has a role of introducing transient DSBs to resolve the concatenated DNA and supercoiling for transcription regulation (TOP2 $\beta$ ) and topological stress during chromosomal segregation and DNA replication (TOP2 $\alpha$ ) [181]. The repair of TOP1- and TOP2 $\beta$-dependent DSBs is mediated by both NHEJ and HR pathways and is often accompanied by PARP1 recruitment to the DNA damage site and induction of PAR synthesis (reviewed in $[182,183])$. This leads to modulation of gene expression at different levels 
including changes in chromatin structure, DNA methylation, and transcription factor recruitment and regulation of their activity (reviewed in $[17,184]$ ). For example, the aforementioned ADP-ribose readers (chromatin remodelers such as ALC1 [84], APLF [79,80]; transcription factors NF-KB [185] and TAF15 [186]; and DNA damage repair proteins, such as XRCC4, Ligase IV, and MRN [75]) are recruited to the DSB sites by noncovalent PAR binding, frequently becoming a substrate of subsequent PARP1-dependent PARylation as well. Recent research revealed that RNA polymerase II and PARP1-dependent NELF (negative elongation factor) complex recruitment is required for DSB-induced transcriptional repression [187], but concurrently, PARP1-catalyzed PARylation of NELF-E and NELF-A inhibits NELF and promotes transcription elongation [188]. Another example of topoisomerase-dependent and PARP1-dependent gene expression is believed to be TP53 expression. TP53 is split into two epigenetic domains depending on its chromatin organization and methylation [189]. Accordingly, the first domain—specifically the promoter region of TP53-is hypomethylated, despite being rich in epigenetic histone markers $\mathrm{H} 3 \mathrm{~K} 9 \mathrm{ac}, \mathrm{H} 3 \mathrm{~K} 4 \mathrm{me} 2, \mathrm{H} 3 \mathrm{~K} 4 \mathrm{me} 3$, and H4K16ac, which are involved in the regulation of active gene transcription [189]. Furthermore, TOP2, PARP1, HDAC, DNMT1, and CTCF have been found to be localized to this region and additionally with TOP1 and BRG1 (chromatin-remodeling ATPase) in the hypermethylated $2^{\text {nd }}$ domain [189]. One possibility is that the hypomethylated status of the promoter region and epigenetic regulation are maintained by the inhibitory effect of PARP1-dependent ADPribosylation on DNMT1 as well as by recruitment of CTCF via its PBZ domain [77] after TOP2coupled DNA damage $[9,160]$.

Notably, DNA repair and/or processing of transcription and/or topoisomerase-induced DNA damage lead to the formation of terminally phosphorylated DNA breaks that can be targeted for PARP-dependent DNA ADP-ribosylation as discussedearlier. Thus, TOP1cc removal depends primarily on the TDP1-driven excision of the 3'-tyrosine adduct that generates a 3 'phosphorylated terminus [190]. It has been reported that TDP1 directly interacts with PARP1 and that they are epistatic for the repair of Top1ccs [191]. DSB processing during alternative 
NHEJ or HR pathways goes through formation of $5^{\prime}$ protruding ends also shown to be effective substrates for PARP1-catalyzed PARylation [13,14]. Moreover, PARP1 is activated by DNA secondary structures like DNA hairpins, G4, and stably unpaired regions [192], whose presence at promoter and enhancer sites in the proximity of a DSB will create alternative PARP1 activation or binding sites for the modification of DNA termini. Notably, PARP3dependent suppression of G4 in response to DNA damage was recently reported [193]. PARP3 deficiency leads to an increase in the content of G4 in G4-rich regions at the sites flanking DSBs, but the molecular mechanism of PARP3 activity at G4 sites remains unknown [193]. It is possible that ADP-ribosylation of DSB termini in these cases will temporarily block their processing or degradation and modulate DNA break signaling, coordinating the choice of a repair mechanism and transcription.

\section{Concluding Remarks}

Besides the well-known biological roles of PARPs such as DNA repair, chromatin modification, and gene expression regulation, these enzymes might also be involved in the programmed DNA strand break-dependent regulation of transcription and replication. The majority of genes regulated by PARPs belong to stress-responsive and differentiation-related genes. This observation suggests that DNA strand breaks may be required also for the regulation of expression of some genes among others listedearlier. The recruitment of effectors-whether via nonspecific surface charge binding or through specific interaction with PAR or MAR adducts covalently linked to protein or DNA—may initiate a signaling cascade of epigenetic changes in chromatin, which result in modulation of the patterns of gene expression (Figure 4).

It is tempting to speculate that the PARP-dependent regulation of gene expression involves transient DNA strand breaks at specific promoter sites, which induce ADP-ribosylation of not only of PARPs themselves and other nuclear proteins, but also DNA strand breaks termini, therefore leading to the recruitment of specific DNA repair and transcription factors to the 
methylation-free gene promoters. However, this hypothesis awaits confirmation from further technically advanced studies. In the meantime, PARylated DNA along with auto-PARylated PARP1 in proximity may block the access of DNMT1 to DNA and maintain the hypomethylated status, which is prerequisite to gene expression. This idea may also be valid to the regulation of expression of $p 16$ and RASSF1A, which are dependent on the presence of PAR [163]. One of the common features of DNMT1, p16, and RASSF1A is that they are all CTCF target genes $[66,163]$; in addition, both $\mathrm{p} 16$ and RASSF1A take part in cell cycle regulation and arrest during DNA damage response [194-196]. Alternatively, covalent ADP-ribosylation of DNA strand break termini may retard the repair, and this in part may explain the phenomenon of the longlived DSBs produced by TOP2 in complex with PARP1 at the promoters of genes, which are regulated by the signal-dependent mechanism, such as PSA, RARb, DIO1 and MMP12, and ERa (estrogen receptor- $\alpha$ ) target genes [180]. Notably, androgen-induced TOP2 $\beta$-mediated DSBs could be detected even $6 \mathrm{~h}$ after hormone stimulation [197].

In addition, new roles of PARPs and PARylation in the RNA biology are emerging. Very recently, using RNA immunoprecipitation it was shown that PARP1 binds thousands of mRNAs and long noncoding RNAs as well as hundreds of small nuclear RNAs and small nucleolar RNAs (snoRNAs). PARP1 binding to snoRNAs leads to its activation and autoPARylation, recruitment, and PARylation of DDX21, an RNA helicase, which, in turn, promotes ribosomal DNA transcription when ADP-ribosylated [198]. Noteworthy, activation of PARPs when bound to RNA or DNA substrates creates a possibility that terminal phosphate residue in proximity to their CAT domain can be ADP-ribosylated. Whether noncanonical RNAs are naturally occurring ADPr acceptors in a living cell remains to be examined in future studies.

At present, it is not clear how specificity of PAR and MAR readers is affected by the nature of ADP-ribosylated target protein residue. Similarly, the specific binding factors of DNA-MAR or DNA-PAR adducts are not yet known, but it is tempting to speculate that they should recognize both the DNA/RNA and ADPr-phosphate moiety. One of the possible readers of ADPribosylated DNA strand breaks termini could be aprataxin, which recognizes an ADP residue 
on 5' termini of a DNA break formed during an abortive DNA ligation reaction and catalyzes the release of the AMP group [199]. Aprataxin interacts with PARP1, which promotes the recruitment of aprataxin to the sites of DNA breaks [200,201]. The PAR-binding affinity of the FHA domain of aprataxin may also contribute to its recruitment to the site of nicked DNA. Hence, due to structural similarities, the MAR unit at a DNA strand break end $[14,112]$ may also be a good substrate for aprataxin activity along with recruitment of XRCC1 or XRCC4, depending on the nature of the DNA strand break, to finalize the repair of DNA damage via BER or NHEJ, respectively [199].

In conclusion, recent biochemical, structural, and cellular studies have expanded our understanding of the diverse roles of ADP-ribosylation. However, new technologies and tools are required for future studies to reliably distinguish ADP-ribosylated proteins and ADPribosylated DNA or RNA products in a live cell, to identify target- and site-specific ADPr readers, and to reveal the functional relevance of site-specific ADP-ribosylation on individual targets $[14,41,202]$.

\section{Acknowledgments}

This work is supported by funding from French National Research Agency (ANR-18-CE440008); Electricité de France ; Fondation ARC (PJA-20181208015). E.M. was supported by doctoral fellowship from ABELA FRERES.

\section{References}

[1] Boyer R. (2006). Posttranslational modification of proteins: Expanding nature's inventory. Christopher T. Walsh, Roberts \& Company Publishers, Greenwood Village, CO, 2005, 576 pp., ISBN 0-9747077-3-2, \$98.00. Biochemistry and Molecular Biology Education. 34, 461-462. https://doi.org/10.1002/bmb.2006.494034069996.

[2] Klungland A., Robertson A. B. (2017). Oxidized C5-methyl cytosine bases in DNA: 5Hydroxymethylcytosine; 5-formylcytosine; and 5-carboxycytosine. Free Radic Biol Med. 107, 62-68. https://doi.org/10.1016/j.freeradbiomed.2016.11.038.

[3] Dabin J., Fortuny A., Polo S. E. (2016). Epigenome Maintenance in Response to DNA Damage. Mol Cell. 62, 712-727. https://doi.org/10.1016/j.molcel.2016.04.006.

[4] Vyas S., Matic I., Uchima L., Rood J., Zaja R., Hay R. T., Ahel I., Chang P. (2014). Familywide analysis of poly(ADP-ribose) polymerase activity. Nat Commun. 5, 4426. https://doi.org/10.1038/ncomms5426. 
[5] Hottiger M. O. (2015). Nuclear ADP-Ribosylation and Its Role in Chromatin Plasticity, Cell Differentiation, and Epigenetics. Annu Rev Biochem. 84, 227-263. https://doi.org/10.1146/annurev-biochem-060614-034506.

[6] Qi H., Price B. D., Day T. A. (2019). Multiple Roles for Mono- and Poly(ADP-Ribose) in Regulating Stress Responses. Trends Genet. 35, 159-172. https://doi.org/10.1016/j.tig.2018.12.002.

[7] Bonicalzi M. E., Haince J. F., Droit A., Poirier G. G. (2005). Regulation of poly(ADP-ribose) metabolism by poly(ADP-ribose) glycohydrolase: where and when? Cell Mol Life Sci. 62, 739750. https://doi.org/10.1007/s00018-004-4505-1.

[8] Yu W., Ginjala V., Pant V., Chernukhin I., Whitehead J., Docquier F., Farrar D., Tavoosidana G., Mukhopadhyay R., Kanduri C., Oshimura M., Feinberg A. P., Lobanenkov V., Klenova E., Ohlsson R. (2004). Poly(ADP-ribosyl)ation regulates CTCF-dependent chromatin insulation. Nat Genet. 36, 1105-1110. https://doi.org/10.1038/ng1426.

[9] Guastafierro T., Cecchinelli B., Zampieri M., Reale A., Riggio G., Sthandier O., Zupi G., Calabrese L., Caiafa P. (2008). CCCTC-binding factor activates PARP-1 affecting DNA methylation machinery. J Biol Chem. 283, 21873-21880. https://doi.org/10.1074/jbc.M801170200.

[10] Guetg C., Scheifele F., Rosenthal F., Hottiger M. O., Santoro R. (2012). Inheritance of silent rDNA chromatin is mediated by PARP1 via noncoding RNA. Mol Cell. 45, 790-800. https://doi.org/10.1016/j.molcel.2012.01.024.

[11] Nakano T., Takahashi-Nakaguchi A., Yamamoto M., Watanabe M. (2015). Pierisins and CARP-1: ADP-ribosylation of DNA by ARTCs in butterflies and shellfish. Curr Top Microbiol Immunol. 384, 127-149. https://doi.org/10.1007/82_2014_416.

[12] Jankevicius G., Ariza A., Ahel M., Ahel I. (2016). The Toxin-Antitoxin System DarTG Catalyzes Reversible ADP-Ribosylation of DNA. Mol Cell. 64, 1109-1116. https://doi.org/10.1016/j.molcel.2016.11.014.

[13] Talhaoui I., Lebedeva N. A., Zarkovic G., Saint-Pierre C., Kutuzov M. M., Sukhanova M. V., Matkarimov B. T., Gasparutto D., Saparbaev M. K., Lavrik O. I., Ishchenko A. A. (2016). Poly(ADP-ribose) polymerases covalently modify strand break termini in DNA fragments in vitro. Nucleic Acids Res. 44, 9279-9295. https://doi.org/10.1093/nar/gkw675.

[14] Zarkovic G., Belousova E. A., Talhaoui I., Saint-Pierre C., Kutuzov M. M., Matkarimov B. T., Biard D., Gasparutto D., Lavrik O. I., Ishchenko A. A. (2018). Characterization of DNA ADPribosyltransferase activities of PARP2 and PARP3: new insights into DNA ADP-ribosylation. Nucleic Acids Res. 46, 2417-2431. https://doi.org/10.1093/nar/gkx1318.

[15] Munnur D., Bartlett E., Mikolcevic P., Kirby I. T., Matthias Rack J. G., Mikoc A., Cohen M. S., Ahel I. (2019). Reversible ADP-ribosylation of RNA. Nucleic Acids Res. 47, 5658-5669. https://doi.org/10.1093/nar/gkz305.

[16] Schreiber V., Dantzer F., Ame J. C., de Murcia G. (2006). Poly(ADP-ribose): novel functions for an old molecule. Nat Rev Mol Cell Biol. 7, 517-528. https://doi.org/10.1038/nrm1963.

[17] Posavec Marjanovic M., Crawford K., Ahel I. (2017). PARP, transcription and chromatin modeling. Semin Cell Dev Biol. 63, 102-113. https://doi.org/10.1016/j.semcdb.2016.09.014.

[18] Rodríguez-Vargas J. M., Oliver-Pozo F. J., Dantzer F. (2019). PARP1 and Poly(ADPribosyl)ation Signaling during Autophagy in Response to Nutrient Deprivation. Oxidative Medicine and Cellular Longevity. 2019, 1-15. https://doi.org/10.1155/2019/2641712.

[19] Hottiger M. O., Hassa P. O., Luscher B., Schuler H., Koch-Nolte F. (2010). Toward a unified nomenclature for mammalian ADP-ribosyltransferases. Trends Biochem Sci. 35, 208219. https://doi.org/10.1016/j.tibs.2009.12.003.

[20] Ame J. C., Spenlehauer C., de Murcia G. (2004). The PARP superfamily. Bioessays. 26, 882-893. https://doi.org/10.1002/bies.20085.

[21] Aravind L., Zhang D., de Souza R. F., Anand S., lyer L. M. (2015). The natural history of ADP-ribosyltransferases and the ADP-ribosylation system. Curr Top Microbiol Immunol. 384, 3-32. https://doi.org/10.1007/82_2014_414.

[22] Burkle A. (2005). Poly(ADP-ribose). The most elaborate metabolite of NAD+. FEBS J. 272, 4576-4589. https://doi.org/10.1111/j.1742-4658.2005.04864.x. 
[23] Munnur D., Ahel I. (2017). Reversible mono-ADP-ribosylation of DNA breaks. FEBS J. 284, 4002-4016. https://doi.org/10.1111/febs.14297.

[24] Palazzo L., Mikoc A., Ahel I. (2017). ADP-ribosylation: new facets of an ancient modification. FEBS J. 284, 2932-2946. https://doi.org/10.1111/febs.14078.

[25] Shieh W. M., Ame J. C., Wilson M. V., Wang Z. Q., Koh D. W., Jacobson M. K., Jacobson E. L. (1998). Poly(ADP-ribose) polymerase null mouse cells synthesize ADP-ribose polymers. J. Biol. Chem. 273, 30069-30072.

[26] Poirier G. G., de Murcia G., Jongstra-Bilen J., Niedergang C., Mandel P. (1982). Poly(ADP-ribosyl)ation of polynucleosomes causes relaxation of chromatin structure. Proc Natl Acad Sci U S A. 79, 3423-3427. https://doi.org/10.1073/pnas.79.11.3423.

[27] Krishnakumar R., Kraus W. L. (2010). The PARP side of the nucleus: molecular actions, physiological outcomes, and clinical targets. Mol Cell. 39, 8-24. https://doi.org/10.1016/j.molcel.2010.06.017.

[28] Krishnakumar R., Kraus W. L. (2010). PARP-1 regulates chromatin structure and transcription through a KDM5B-dependent pathway. Mol Cell. 39, 736-749. https://doi.org/10.1016/j.molcel.2010.08.014.

[29] Kraus W. L. (2015). PARPs and ADP-Ribosylation: 50 Years ... and Counting. Mol Cell. 58, 902-910. https://doi.org/10.1016/j.molcel.2015.06.006.

[30] Hanzlikova H., Kalasova I., Demin A. A., Pennicott L. E., Cihlarova Z., Caldecott K. W. (2018). The Importance of Poly(ADP-Ribose) Polymerase as a Sensor of Unligated Okazaki Fragments during DNA Replication. Mol Cell. 71, 319-331 e313. https://doi.org/10.1016/j.molcel.2018.06.004.

[31] Ame J. C., Rolli V., Schreiber V., Niedergang C., Apiou F., Decker P., Muller S., Hoger T., Menissier-de Murcia J., de Murcia G. (1999). PARP-2, A novel mammalian DNA damagedependent poly(ADP-ribose) polymerase. J Biol Chem. 274, 17860-17868.

[32] Menissier de Murcia J., Ricoul M., Tartier L., Niedergang C., Huber A., Dantzer F., Schreiber V., Ame J. C., Dierich A., LeMeur M., Sabatier L., Chambon P., de Murcia G. (2003). Functional interaction between PARP-1 and PARP-2 in chromosome stability and embryonic development in mouse. EMBO J. 22, 2255-2263. https://doi.org/10.1093/emboj/cdg206.

[33] Fouquin A., Guirouilh-Barbat J., Lopez B., Hall J., Amor-Gueret M., Pennaneach V. (2017). PARP2 controls double-strand break repair pathway choice by limiting 53BP1 accumulation at DNA damage sites and promoting end-resection. Nucleic Acids Res. 45, 12325-12339. https://doi.org/10.1093/nar/gkx881.

[34] Bai P. (2015). Biology of Poly(ADP-Ribose) Polymerases: The Factotums of Cell Maintenance. Mol Cell. 58, 947-958. https://doi.org/10.1016/j.molcel.2015.01.034.

[35] Obaji E., Haikarainen T., Lehtio L. (2016). Characterization of the DNA dependent activation of human ARTD2/PARP2. Sci Rep. 6, 34487. https://doi.org/10.1038/srep34487.

[36] Langelier M. F., Riccio A. A., Pascal J. M. (2014). PARP-2 and PARP-3 are selectively activated by 5' phosphorylated DNA breaks through an allosteric regulatory mechanism shared with PARP-1. Nucleic Acids Res. 42, 7762-7775. https://doi.org/10.1093/nar/gku474.

[37] Riccio A. A., Cingolani G., Pascal J. M. (2016). PARP-2 domain requirements for DNA damage-dependent activation and localization to sites of DNA damage. Nucleic Acids Res. 44, 1691-1702. https://doi.org/10.1093/nar/gkv1376.

[38] Gibson B. A., Kraus W. L. (2012). New insights into the molecular and cellular functions of poly(ADP-ribose) and PARPs. Nat Rev Mol Cell Biol. 13, 411-424. https://doi.org/10.1038/nrm3376.

[39] Beck C., Robert I., Reina-San-Martin B., Schreiber V., Dantzer F. (2014). Poly(ADPribose) polymerases in double-strand break repair: focus on PARP1, PARP2 and PARP3. Exp Cell Res. 329, 18-25. https://doi.org/10.1016/j.yexcr.2014.07.003.

[40] Rouleau M., McDonald D., Gagne P., Ouellet M. E., Droit A., Hunter J. M., Dutertre S., Prigent C., Hendzel M. J., Poirier G. G. (2007). PARP-3 associates with polycomb group bodies and with components of the DNA damage repair machinery. J Cell Biochem. 100, 385401. https://doi.org/10.1002/jcb.21051. 
[41] Gupte R., Liu Z., Kraus W. L. (2017). PARPs and ADP-ribosylation: recent advances linking molecular functions to biological outcomes. Genes Dev. 31, 101-126. https://doi.org/10.1101/gad.291518.116.

[42] Palazzo L., Ahel I. (2018). PARPs in genome stability and signal transduction: implications for cancer therapy. Biochem Soc Trans. 46, 1681-1695. https://doi.org/10.1042/BST20180418.

[43] Martin-Hernandez K., Rodriguez-Vargas J. M., Schreiber V., Dantzer F. (2017). Expanding functions of ADP-ribosylation in the maintenance of genome integrity. Semin Cell Dev Biol. 63, 92-101. https://doi.org/10.1016/j.semcdb.2016.09.009.

[44] David K. K., Andrabi S. A., Dawson T. M., Dawson V. L. (2009). Parthanatos, a messenger of death. Front Biosci (Landmark Ed). 14, 1116-1128.

[45] Koh D. W., Lawler A. M., Poitras M. F., Sasaki M., Wattler S., Nehls M. C., Stoger T., Poirier G. G., Dawson V. L., Dawson T. M. (2004). Failure to degrade poly(ADP-ribose) causes increased sensitivity to cytotoxicity and early embryonic lethality. Proc Natl Acad Sci U S A. 101, 17699-17704. https://doi.org/10.1073/pnas.0406182101.

[46] Tang J. B., Svilar D., Trivedi R. N., Wang X. H., Goellner E. M., Moore B., Hamilton R. L., Banze L. A., Brown A. R., Sobol R. W. (2011). N-methylpurine DNA glycosylase and DNA polymerase beta modulate BER inhibitor potentiation of glioma cells to temozolomide. Neuro Oncol. 13, 471-486. https://doi.org/10.1093/neuonc/nor011.

[47] Hatakeyama K., Nemoto Y., Ueda K., Hayaishi O. (1986). Purification and characterization of poly(ADP-ribose) glycohydrolase. Different modes of action on large and small poly(ADP. ribose). J Biol Chem. 261, 14902-14911.

[48] O'Sullivan J., Tedim Ferreira M., Gagne J. P., Sharma A. K., Hendzel M. J., Masson J. Y., Poirier G. G. (2019). Emerging roles of eraser enzymes in the dynamic control of protein ADPribosylation. Nat Commun. 10, 1182. https://doi.org/10.1038/s41467-019-08859-x.

[49] Ogata N., Ueda K., Kagamiyama H., Hayaishi O. (1980). ADP-ribosylation of histone H1. Identification of glutamic acid residues 2, 14, and the $\mathrm{COOH}$-terminal lysine residue as modification sites. J Biol Chem. 255, 7616-7620.

[50] Haenni S. S., Hassa P. O., Altmeyer M., Fey M., Imhof R., Hottiger M. O. (2008). Identification of lysines 36 and 37 of PARP-2 as targets for acetylation and auto-ADPribosylation. Int $\mathrm{J}$ Biochem Cell Biol. 40, 2274-2283. https://doi.org/10.1016/j.biocel.2008.03.008.

[51] Grundy G. J., Polo L. M., Zeng Z., Rulten S. L., Hoch N. C., Paomephan P., Xu Y., Sweet S. M., Thorne A. W., Oliver A. W., Matthews S. J., Pearl L. H., Caldecott K. W. (2016). PARP3 is a sensor of nicked nucleosomes and monoribosylates histone H2B(Glu2). Nat Commun. 7, 12404. https://doi.org/10.1038/ncomms 12404 .

[52] Messner S., Altmeyer M., Zhao H., Pozivil A., Roschitzki B., Gehrig P., Rutishauser D., Huang D., Caflisch A., Hottiger M. O. (2010). PARP1 ADP-ribosylates lysine residues of the core histone tails. Nucleic Acids Res. 38, 6350-6362. https://doi.org/10.1093/nar/gkq463.

[53] Altmeyer M., Messner S., Hassa P. O., Fey M., Hottiger M. O. (2009). Molecular mechanism of poly(ADP-ribosyl)ation by PARP1 and identification of lysine residues as ADPribose acceptor sites. Nucleic Acids Res. 37, 3723-3738. https://doi.org/10.1093/nar/gkp229.

[54] Zhang Y., Wang J., Ding M., Yu Y. (2013). Site-specific characterization of the Asp- and Glu-ADP-ribosylated proteome. Nat Methods. 10, 981-984. https://doi.org/10.1038/nmeth.2603.

[55] Martello R., Leutert M., Jungmichel S., Bilan V., Larsen S. C., Young C., Hottiger M. O., Nielsen M. L. (2016). Proteome-wide identification of the endogenous ADP-ribosylome of mammalian cells and tissue. Nat Commun. 7, 12917. https://doi.org/10.1038/ncomms12917.

[56] Bonfiglio J. J., Fontana P., Zhang Q., Colby T., Gibbs-Seymour I., Atanassov I., Bartlett E., Zaja R., Ahel I., Matic I. (2017). Serine ADP-Ribosylation Depends on HPF1. Mol Cell. 65, 932-940 e936. https://doi.org/10.1016/j.molcel.2017.01.003.

[57] Palazzo L., Leidecker O., Prokhorova E., Dauben H., Matic I., Ahel I. (2018). Serine is the major residue for ADP-ribosylation upon DNA damage. Elife. 7, e34334. https://doi.org/10.7554/eLife.34334. 
[58] Kalesh K., Lukauskas S., Borg A. J., Snijders A. P., Ayyappan V., Leung A. K. L., Haskard D. O., DiMaggio P. A. (2019). An Integrated Chemical Proteomics Approach for Quantitative Profiling of Intracellular ADP-Ribosylation. Sci Rep. 9, 6655. https://doi.org/10.1038/s41598019-43154-1.

[59] Hendriks I. A., Larsen S. C., Nielsen M. L. (2019). An Advanced Strategy for Comprehensive Profiling of ADP-ribosylation Sites Using Mass Spectrometry-based Proteomics. Mol Cell Proteomics. 18, 1010-1026. https://doi.org/10.1074/mcp.TIR119.001315. [60] Bartlett E., Bonfiglio J. J., Prokhorova E., Colby T., Zobel F., Ahel I., Matic I. (2018). Interplay of Histone Marks with Serine ADP-Ribosylation. Cell Rep. 24, 3488-3502.e3485. https://doi.org/10.1016/j.celrep.2018.08.092.

[61] Abplanalp J., Leutert M., Frugier E., Nowak K., Feurer R., Kato J., Kistemaker H. V. A., Filippov D. V., Moss J., Caflisch A., Hottiger M. O. (2017). Proteomic analyses identify ARH3 as a serine mono-ADP-ribosylhydrolase. Nat Commun. 8, 2055. https://doi.org/10.1038/s41467-017-02253-1.

[62] Fontana P., Bonfiglio J. J., Palazzo L., Bartlett E., Matic I., Ahel I. (2017). Serine ADPribosylation reversal by the hydrolase ARH3. Elife. 6, e28533. https://doi.org/10.7554/eLife.28533.

[63] Mashimo M., Kato J., Moss J. (2013). ADP-ribosyl-acceptor hydrolase 3 regulates poly (ADP-ribose) degradation and cell death during oxidative stress. Proc Natl Acad Sci U S A. 110, 18964-18969. https://doi.org/10.1073/pnas.1312783110.

[64] Leslie Pedrioli D. M., Leutert M., Bilan V., Nowak K., Gunasekera K., Ferrari E., Imhof R., Malmstrom L., Hottiger M. O. (2018). Comprehensive ADP-ribosylome analysis identifies tyrosine as an ADP-ribose acceptor site. EMBO Rep. 19, e45310. https://doi.org/10.15252/embr.201745310.

[65] Ord M. G., Stocken L. A. (1977). Adenosine diphosphate ribosylated histones. Biochem J. 161, 583-592.

[66] Ciccarone F., Zampieri M., Caiafa P. (2017). PARP1 orchestrates epigenetic events setting up chromatin domains. Semin Cell Dev Biol. 63, 123-134. https://doi.org/10.1016/j.semcdb.2016.11.010.

[67] Fischbach A., Kruger A., Hampp S., Assmann G., Rank L., Hufnagel M., Stockl M. T., Fischer J. M. F., Veith S., Rossatti P., Ganz M., Ferrando-May E., Hartwig A., Hauser K., Wiesmuller L., Burkle A., Mangerich A. (2018). The C-terminal domain of p53 orchestrates the interplay between non-covalent and covalent poly(ADP-ribosyl)ation of p53 by PARP1. Nucleic Acids Res. 46, 804-822. https://doi.org/10.1093/nar/gkx1205.

[68] Verheugd P., Forst A. H., Milke L., Herzog N., Feijs K. L., Kremmer E., Kleine H., Luscher B. (2013). Regulation of NF-kappaB signalling by the mono-ADP-ribosyltransferase ARTD10. Nat Commun. 4, 1683. https://doi.org/10.1038/ncomms2672.

[69] Pleschke J. M., Kleczkowska H. E., Strohm M., Althaus F. R. (2000). Poly(ADP-ribose) binds to specific domains in DNA damage checkpoint proteins. J Biol Chem. 275, 4097440980. https://doi.org/10.1074/jbc.M006520200.

[70] Gagne J. P., Isabelle M., Lo K. S., Bourassa S., Hendzel M. J., Dawson V. L., Dawson T. M., Poirier G. G. (2008). Proteome-wide identification of poly(ADP-ribose) binding proteins and poly(ADP-ribose)-associated protein complexes. Nucleic Acids Res. 36, 6959-6976. https://doi.org/10.1093/nar/gkn771.

[71] Oberoi J., Richards M. W., Crumpler S., Brown N., Blagg J., Bayliss R. (2010). Structural basis of poly(ADP-ribose) recognition by the multizinc binding domain of checkpoint with forkhead-associated and RING Domains (CHFR). J Biol Chem. 285, 39348-39358. https://doi.org/10.1074/jbc.M110.159855.

[72] Ahel I., Ahel D., Matsusaka T., Clark A. J., Pines J., Boulton S. J., West S. C. (2008). Poly(ADP-ribose)-binding zinc finger motifs in DNA repair/checkpoint proteins. Nature. 451, 81-85. https://doi.org/10.1038/nature06420.

[73] Li G. Y., McCulloch R. D., Fenton A. L., Cheung M., Meng L., Ikura M., Koch C. A. (2010). Structure and identification of ADP-ribose recognition motifs of APLF and role in the DNA damage response. Proc Natl Acad Sci U S A. 107, 9129-9134. https://doi.org/10.1073/pnas.1000556107. 
[74] Wang Z., Michaud G. A., Cheng Z., Zhang Y., Hinds T. R., Fan E., Cong F., Xu W. (2012). Recognition of the iso-ADP-ribose moiety in poly(ADP-ribose) by WWE domains suggests a general mechanism for poly(ADP-ribosyl)ation-dependent ubiquitination. Genes Dev. 26, 235240. https://doi.org/10.1101/gad.182618.111.

[75] Li M., Lu L. Y., Yang C. Y., Wang S., Yu X. (2013). The FHA and BRCT domains recognize ADP-ribosylation during DNA damage response. Genes Dev. 27, 1752-1768. https://doi.org/10.1101/gad.226357.113.

[76] Karras G. I., Kustatscher G., Buhecha H. R., Allen M. D., Pugieux C., Sait F., Bycroft M., Ladurner A. G. (2005). The macro domain is an ADP-ribose binding module. EMBO J. 24, 1911-1920. https://doi.org/10.1038/sj.emboj.7600664.

[77] Teloni F., Altmeyer M. (2016). Readers of poly(ADP-ribose): designed to be fit for purpose. Nucleic Acids Res. 44, 993-1006. https://doi.org/10.1093/nar/gkv1383.

[78] Vivelo C. A., Wat R., Agrawal C., Tee H. Y., Leung A. K. (2017). ADPriboDB: The database of ADP-ribosylated proteins. Nucleic Acids Res. 45, D204-D209. https://doi.org/10.1093/nar/gkw706.

[79] Rulten S. L., Fisher A. E., Robert I., Zuma M. C., Rouleau M., Ju L., Poirier G., Reina-SanMartin B., Caldecott K. W. (2011). PARP-3 and APLF function together to accelerate nonhomologous end-joining. Mol Cell. 41, 33-45. https://doi.org/10.1016/j.molcel.2010.12.006. [80] Chen Q., Kassab M. A., Dantzer F., Yu X. (2018). PARP2 mediates branched poly ADPribosylation in response to DNA damage. Nat Commun. 9, 3233. https://doi.org/10.1038/s41467-018-05588-5.

[81] Posavec Marjanovic M., Hurtado-Bages S., Lassi M., Valero V., Malinverni R., Delage H., Navarro M., Corujo D., Guberovic I., Douet J., Gama-Perez P., Garcia-Roves P. M., Ahel I., Ladurner A. G., Yanes O., Bouvet P., Suelves M., Teperino R., Pospisilik J. A., Buschbeck M. (2017). MacroH2A1.1 regulates mitochondrial respiration by limiting nuclear $\mathrm{NAD}(+)$ consumption. Nat Struct Mol Biol. 24, 902-910. https://doi.org/10.1038/nsmb.3481.

[82] Hurtado-Bages S., Guberovic I., Buschbeck M. (2018). The MacroH2A1.1 - PARP1 Axis at the Intersection Between Stress Response and Metabolism. Front Genet. 9, 417. https://doi.org/10.3389/fgene.2018.00417.

[83] Xu C., Xu Y., Gursoy-Yuzugullu O., Price B. D. (2012). The histone variant macroH2A1.1 is recruited to DSBs through a mechanism involving PARP1. FEBS Lett. 586, 3920-3925. https://doi.org/10.1016/j.febslet.2012.09.030.

[84] Singh H. R., Nardozza A. P., Moller I. R., Knobloch G., Kistemaker H. A. V., Hassler M., Harrer N., Blessing C., Eustermann S., Kotthoff C., Huet S., Mueller-Planitz F., Filippov D. V., Timinszky G., Rand K. D., Ladurner A. G. (2017). A Poly-ADP-Ribose Trigger Releases the Auto-Inhibition of a Chromatin Remodeling Oncogene. Mol Cell. 68, 860-871.e867. https://doi.org/10.1016/j.molcel.2017.11.019.

[85] Feijs K. L., Forst A. H., Verheugd P., Luscher B. (2013). Macrodomain-containing proteins: regulating new intracellular functions of mono(ADP-ribosyl)ation. Nat Rev Mol Cell Biol. 14, 443-451. https://doi.org/10.1038/nrm3601.

[86] Forst A. H., Karlberg T., Herzog N., Thorsell A. G., Gross A., Feijs K. L., Verheugd P., Kursula P., Nijmeijer B., Kremmer E., Kleine H., Ladurner A. G., Schuler H., Luscher B. (2013). Recognition of mono-ADP-ribosylated ARTD10 substrates by ARTD8 macrodomains. Structure. 21, 462-475. https://doi.org/10.1016/j.str.2012.12.019.

[87] Rosenthal F., Feijs K. L., Frugier E., Bonalli M., Forst A. H., Imhof R., Winkler H. C., Fischer D., Caflisch A., Hassa P. O., Luscher B., Hottiger M. O. (2013). Macrodomain-containing proteins are new mono-ADP-ribosylhydrolases. Nat Struct Mol Biol. 20, 502-507. https://doi.org/10.1038/nsmb.2521.

[88] DaRosa P. A., Wang Z., Jiang X., Pruneda J. N., Cong F., Klevit R. E., Xu W. (2015). Allosteric activation of the RNF146 ubiquitin ligase by a poly(ADP-ribosyl)ation signal. Nature. 517, 223-226. https://doi.org/10.1038/nature13826.

[89] Aravind L. (2001). The WWE domain: a common interaction module in protein ubiquitination and ADP ribosylation. Trends Biochem Sci. 26, 273-275.

[90] Durocher D., Jackson S. P. (2002). The FHA domain. FEBS Lett. 513, 58-66. https://doi.org/10.1016/s0014-5793(01)03294-x. 
[91] Yu X., Chini C. C., He M., Mer G., Chen J. (2003). The BRCT domain is a phospho-protein binding domain. Science. 302, 639-642. https://doi.org/10.1126/science.1088753.

[92] Li M., Yu X. (2013). Function of BRCA1 in the DNA damage response is mediated by ADP-ribosylation. Cancer Cell. 23, 693-704. https://doi.org/10.1016/j.ccr.2013.03.025.

[93] Breslin C., Hornyak P., Ridley A., Rulten S. L., Hanzlikova H., Oliver A. W., Caldecott K. W. (2015). The XRCC1 phosphate-binding pocket binds poly (ADP-ribose) and is required for XRCC1 function. Nucleic Acids Res. 43, 6934-6944. https://doi.org/10.1093/nar/gkv623.

[94] Polo L. M., Xu Y., Hornyak P., Garces F., Zeng Z., Hailstone R., Matthews S. J., Caldecott K. W., Oliver A. W., Pearl L. H. (2019). Efficient Single-Strand Break Repair Requires Binding to Both Poly(ADP-Ribose) and DNA by the Central BRCT Domain of XRCC1. Cell Rep. 26, 573-581.e575. https://doi.org/10.1016/j.celrep.2018.12.082.

[95] Krietsch J., Caron M. C., Gagne J. P., Ethier C., Vignard J., Vincent M., Rouleau M., Hendzel M. J., Poirier G. G., Masson J. Y. (2012). PARP activation regulates the RNA-binding protein NONO in the DNA damage response to DNA double-strand breaks. Nucleic Acids Res. 40, 10287-10301. https://doi.org/10.1093/nar/gks798.

[96] Malanga M., Czubaty A., Girstun A., Staron K., Althaus F. R. (2008). Poly(ADP-ribose) binds to the splicing factor ASF/SF2 and regulates its phosphorylation by DNA topoisomerase I. J Biol Chem. 283, 19991-19998. https://doi.org/10.1074/jbc.M709495200.

[97] Bock F. J., Todorova T. T., Chang P. (2015). RNA Regulation by Poly(ADP-Ribose) Polymerases. Mol Cell. 58, 959-969. https://doi.org/10.1016/j.molcel.2015.01.037.

[98] Ke Y., Zhang J., Lv X., Zeng X., Ba X. (2019). Novel insights into PARPs in gene expression: regulation of RNA metabolism. Cell Mol Life Sci. 76, 3283-3299. https://doi.org/10.1007/s00018-019-03120-6.

[99] Murawska M., Hassler M., Renkawitz-Pohl R., Ladurner A., Brehm A. (2011). Stressinduced PARP activation mediates recruitment of Drosophila Mi-2 to promote heat shock gene expression. PLoS Genet. 7, e1002206. https://doi.org/10.1371/journal.pgen.1002206.

[100] Zhang F., Chen Y., Li M., Yu X. (2014). The oligonucleotide/oligosaccharide-binding fold motif is a poly(ADP-ribose)-binding domain that mediates DNA damage response. Proc Natl Acad Sci U S A. 111, 7278-7283. https://doi.org/10.1073/pnas.1318367111.

[101] Senissar M., Manav M. C., Brodersen D. E. (2017). Structural conservation of the PIN domain active site across all domains of life. Protein Sci. 26, 1474-1492. https://doi.org/10.1002/pro.3193.

[102] Zhang F., Shi J., Chen S. H., Bian C., Yu X. (2015). The PIN domain of EXO1 recognizes poly(ADP-ribose) in DNA damage response. Nucleic Acids Res. 43, 10782-10794. https://doi.org/10.1093/nar/gkv939.

[103] Chen J. K., Lin W. L., Chen Z., Liu H. W. (2018). PARP-1-dependent recruitment of coldinducible RNA-binding protein promotes double-strand break repair and genome stability. Proc Natl Acad Sci U S A. 115, E1759-e1768. https://doi.org/10.1073/pnas.1713912115.

[104] Watanabe M., Kono T., Matsushima-Hibiya Y., Kanazawa T., Nishisaka N., Kishimoto T., Koyama K., Sugimura T., Wakabayashi K. (1999). Molecular cloning of an apoptosis-inducing protein, pierisin, from cabbage butterfly: possible involvement of ADP-ribosylation in its activity. Proc Natl Acad Sci U S A. 96, 10608-10613. https://doi.org/10.1073/pnas.96.19.10608.

[105] Takamura-Enya T., Watanabe M., Totsuka Y., Kanazawa T., Matsushima-Hibiya Y., Koyama K., Sugimura T., Wakabayashi K. (2001). Mono(ADP-ribosyl)ation of 2'deoxyguanosine residue in DNA by an apoptosis-inducing protein, pierisin-1, from cabbage butterfly. Proc Natl Acad Sci U S A. 98, 12414-12419. https://doi.org/10.1073/pnas.221444598.

[106] Lyons B., Ravulapalli R., Lanoue J., Lugo M. R., Dutta D., Carlin S., Merrill A. R. (2016). Scabin, a Novel DNA-acting ADP-ribosyltransferase from Streptomyces scabies. J Biol Chem. 291, 11198-11215. https://doi.org/10.1074/jbc.M115.707653.

[107] Eustermann S., Wu W. F., Langelier M. F., Yang J. C., Easton L. E., Riccio A. A., Pascal J. M., Neuhaus D. (2015). Structural Basis of Detection and Signaling of DNA Single-Strand Breaks by Human PARP-1. Mol Cell. 60, 742-754. https://doi.org/10.1016/j.molcel.2015.10.032. 
[108] Dawicki-McKenna J. M., Langelier M. F., DeNizio J. E., Riccio A. A., Cao C. D., Karch K. R., McCauley M., Steffen J. D., Black B. E., Pascal J. M. (2015). PARP-1 Activation Requires Local Unfolding of an Autoinhibitory Domain. Mol Cell. 60, 755-768. https://doi.org/10.1016/j.molcel.2015.10.013.

[109] Sacho E. J., Maizels N. (2011). DNA repair factor MRE11/RAD50 cleaves 3'phosphotyrosyl bonds and resects DNA to repair damage caused by topoisomerase 1 poisons. J Biol Chem. 286, 44945-44951. https://doi.org/10.1074/jbc.M111.299347.

[110] Kawale A. S., Povirk L. F. (2018). Tyrosyl-DNA phosphodiesterases: rescuing the genome from the risks of relaxation. Nucleic Acids Res. 46, 520-537. https://doi.org/10.1093/nar/gkx1219.

[111] Anand R., Ranjha L., Cannavo E., Cejka P. (2016). Phosphorylated CtIP Functions as a Co-factor of the MRE11-RAD50-NBS1 Endonuclease in DNA End Resection. Mol Cell. 64, 940-950. https://doi.org/10.1016/j.molcel.2016.10.017.

[112] Belousova E. A., Ishchenko A. A., Lavrik O. I. (2018). DNA is a New Target of PARP3. Sci Rep. 8, 4176. https://doi.org/10.1038/s41598-018-22673-3.

[113] Fouquerel E., Goellner E. M., Yu Z., Gagne J. P., Barbi de Moura M., Feinstein T., Wheeler D., Redpath P., Li J., Romero G., Migaud M., Van Houten B., Poirier G. G., Sobol R. W. (2014). ARTD1/PARP1 negatively regulates glycolysis by inhibiting hexokinase 1 independent of NAD+ depletion. Cell Rep. 8, 1819-1831. https://doi.org/10.1016/j.celrep.2014.08.036.

[114] Munir A., Banerjee A., Shuman S. (2018). NAD+-dependent synthesis of a 5'-phosphoADP-ribosylated RNA/DNA cap by RNA 2'-phosphotransferase Tpt1. Nucleic Acids Res. 46, 9617-9624. https://doi.org/10.1093/nar/gky792.

[115] Banerjee A., Munir A., Abdullahu L., Damha M. J., Goldgur Y., Shuman S. (2019). Structure of tRNA splicing enzyme Tpt1 illuminates the mechanism of RNA 2'-PO4 recognition and ADP-ribosylation. Nat Commun. 10, 218. https://doi.org/10.1038/s41467-018-08211-9.

[116] Agnew T., Munnur D., Crawford K., Palazzo L., Mikoc A., Ahel I. (2018). MacroD1 Is a Promiscuous ADP-Ribosyl Hydrolase Localized to Mitochondria. Front Microbiol. 9, 20. https://doi.org/10.3389/fmicb.2018.00020.

[117] Bednarski J. J., Sleckman B. P. (2019). At the intersection of DNA damage and immune responses. Nat Rev Immunol. 19, 231-242. https://doi.org/10.1038/s41577-019-0135-6.

[118] Dudley D. D., Chaudhuri J., Bassing C. H., Alt F. W. (2005). Mechanism and control of $\mathrm{V}(\mathrm{D}) \mathrm{J}$ recombination versus class switch recombination: similarities and differences. Adv Immunol. 86, 43-112. https://doi.org/10.1016/s0065-2776(04)86002-4.

[119] Bednarski J. J., Sleckman B. P. (2012). Lymphocyte development: integration of DNA damage response signaling. Adv Immunol. 116, 175-204. https://doi.org/10.1016/b978-0-12394300-2.00006-5.

[120] Keim C., Kazadi D., Rothschild G., Basu U. (2013). Regulation of AID, the B-cell genome mutator. Genes Dev. 27, 1-17. https://doi.org/10.1101/gad.200014.112.

[121] Santos F., Peat J., Burgess H., Rada C., Reik W., Dean W. (2013). Active demethylation in mouse zygotes involves cytosine deamination and base excision repair. Epigenetics Chromatin. 6, 39. https://doi.org/10.1186/1756-8935-6-39.

[122] Franchini D. M., Chan C. F., Morgan H., Incorvaia E., Rangam G., Dean W., Santos F., Reik W., Petersen-Mahrt S. K. (2014). Processive DNA demethylation via DNA deaminaseinduced lesion resolution. PLoS One. 9, e97754. https://doi.org/10.1371/journal.pone.0097754.

[123] Barreto G., Schafer A., Marhold J., Stach D., Swaminathan S. K., Handa V., Doderlein G., Maltry N., Wu W., Lyko F., Niehrs C. (2007). Gadd45a promotes epigenetic gene activation by repair-mediated DNA demethylation. Nature. 445, 671-675. https://doi.org/10.1038/nature05515.

[124] Grin I., Ishchenko A. A. (2016). An interplay of the base excision repair and mismatch repair pathways in active DNA demethylation. Nucleic Acids Res. 44, 3713-3727. https://doi.org/10.1093/nar/gkw059. 
[125] Le Q., Maizels N. (2015). Cell Cycle Regulates Nuclear Stability of AID and Determines the Cellular Response to AID. PLoS Genet. 11, e1005411. https://doi.org/10.1371/journal.pgen.1005411.

[126] Endo Y., Marusawa H., Kinoshita K., Morisawa T., Sakurai T., Okazaki I. M., Watashi K., Shimotohno K., Honjo T., Chiba T. (2007). Expression of activation-induced cytidine deaminase in human hepatocytes via NF-kappaB signaling. Oncogene. 26, 5587-5595. https://doi.org/10.1038/sj.onc.1210344.

[127] Duan Z., Zheng H., Liu H., Li M., Tang M., Weng X., Yi W., Bode A. M., Cao Y. (2016). AID expression increased by TNF-alpha is associated with class switch recombination of Igalpha gene in cancers. Cell Mol Immunol. 13, 484-491. https://doi.org/10.1038/cmi.2015.26. [128] Chaudhuri J., Tian M., Khuong C., Chua K., Pinaud E., Alt F. W. (2003). Transcriptiontargeted DNA deamination by the AID antibody diversification enzyme. Nature. 422, 726-730. https://doi.org/10.1038/nature01574.

[129] Qiao Q., Wang L., Meng F. L., Hwang J. K., Alt F. W., Wu H. (2017). AID Recognizes Structured DNA for Class Switch Recombination. Mol Cell. 67, 361-373 e364. https://doi.org/10.1016/j.molcel.2017.06.034.

[130] Al-Khalaf M. H., Blake L. E., Larsen B. D., Bell R. A., Brunette S., Parks R. J., Rudnicki M. A., McKinnon P. J., Jeffrey Dilworth F., Megeney L. A. (2016). Temporal activation of XRCC1-mediated DNA repair is essential for muscle differentiation. Cell Discov. 2, 15041. https://doi.org/10.1038/celldisc.2015.41.

[131] Farzaneh F., Zalin R., Brill D., Shall S. (1982). DNA strand breaks and ADP-ribosyl transferase activation during cell differentiation. Nature. 300, 362-366. https://doi.org/10.1038/300362a0.

[132] Dawson B. A., Lough J. (1988). Immunocytochemical localization of transient DNA strand breaks in differentiating myotubes using in situ nick-translation. Dev Biol. 127, 362-367.

[133] Eustermann S., Videler H., Yang J. C., Cole P. T., Gruszka D., Veprintsev D., Neuhaus D. (2011). The DNA-binding domain of human PARP-1 interacts with DNA single-strand breaks as a monomer through its second zinc finger. $J$ Mol Biol. 407, 149-170. https://doi.org/10.1016/j.jmb.2011.01.034.

[134] Larsen B. D., Rampalli S., Burns L. E., Brunette S., Dilworth F. J., Megeney L. A. (2010). Caspase 3/caspase-activated DNase promote cell differentiation by inducing DNA strand breaks. Proc Natl Acad Sci U S A. 107, 4230-4235. https://doi.org/10.1073/pnas.0913089107. [135] Carrio E., Suelves M. (2015). DNA methylation dynamics in muscle development and disease. Front Aging Neurosci. 7, 19. https://doi.org/10.3389/fnagi.2015.00019.

[136] Azad G. K., Ito K., Sailaja B. S., Biran A., Nissim-Rafinia M., Yamada Y., Brown D. T., Takizawa T., Meshorer E. (2018). PARP1-dependent eviction of the linker histone $\mathrm{H} 1$ mediates immediate early gene expression during neuronal activation. J Cell Biol. 217, 473-481. https://doi.org/10.1083/jcb.201703141.

[137] Vicent G. P., Wright R. H., Beato M. (2016). Linker histones in hormonal gene regulation. Biochim Biophys Acta. 1859, 520-525. https://doi.org/10.1016/j.bbagrm.2015.10.016.

[138] Huang X., LeDuc R. D., Fornelli L., Schunter A. J., Bennett R. L., Kelleher N. L., Licht J. D. (2019). Defining the NSD2 interactome: PARP1 PARylation reduces NSD2 histone methyltransferase activity and impedes chromatin binding. J Biol Chem. 294, 12459-12471. https://doi.org/10.1074/jbc.RA118.006159.

[139] Moore L. D., Le T., Fan G. (2013). DNA methylation and its basic function. Neuropsychopharmacology. 38, 23-38. https://doi.org/10.1038/npp.2012.112.

[140] Deaton A. M., Bird A. (2011). CpG islands and the regulation of transcription. Genes Dev. 25, 1010-1022. https://doi.org/10.1101/gad.2037511.

[141] Ross S. E., Bogdanovic O. (2019). TET enzymes, DNA demethylation and pluripotency. Biochem Soc Trans. 47, 875-885. https://doi.org/10.1042/BST20180606.

[142] Gavin D. P., Chase K. A., Sharma R. P. (2013). Active DNA demethylation in post-mitotic neurons: a reason for optimism. Neuropharmacology. 75, 233-245. https://doi.org/10.1016/j.neuropharm.2013.07.036.

[143] Cedar H., Bergman Y. (2009). Linking DNA methylation and histone modification: patterns and paradigms. Nat Rev Genet. 10, 295-304. https://doi.org/10.1038/nrg2540. 
[144] Lang Z., Lei M., Wang X., Tang K., Miki D., Zhang H., Mangrauthia S. K., Liu W., Nie W., Ma G., Yan J., Duan C. G., Hsu C. C., Wang C., Tao W. A., Gong Z., Zhu J. K. (2015). The methyl-CpG-binding protein MBD7 facilitates active DNA demethylation to limit DNA hypermethylation and transcriptional gene silencing. Mol Cell. 57, 971-983. https://doi.org/10.1016/j.molcel.2015.01.009.

[145] Bochtler M., Kolano A., Xu G. L. (2017). DNA demethylation pathways: Additional players and regulators. Bioessays. 39, 1-13. https://doi.org/10.1002/bies.201600178.

[146] Rai K., Huggins I. J., James S. R., Karpf A. R., Jones D. A., Cairns B. R. (2008). DNA demethylation in zebrafish involves the coupling of a deaminase, a glycosylase, and gadd45. Cell. 135, 1201-1212. https://doi.org/10.1016/j.cell.2008.11.042.

[147] Chen C. C., Wang K. Y., Shen C. K. (2013). DNA 5-methylcytosine demethylation activities of the mammalian DNA methyltransferases. J Biol Chem. 288, 9084-9091. https://doi.org/10.1074/jbc.M112.445585.

[148] Rebhandl S., Huemer M., Greil R., Geisberger R. (2015). AID/APOBEC deaminases and cancer. Oncoscience. 2, 320-333. https://doi.org/10.18632/oncoscience.155.

[149] He Y. F., Li B. Z., Li Z., Liu P., Wang Y., Tang Q., Ding J., Jia Y., Chen Z., Li L., Sun Y., Li X., Dai Q., Song C. X., Zhang K., He C., Xu G. L. (2011). Tet-mediated formation of 5carboxylcytosine and its excision by TDG in mammalian DNA. Science. 333, 1303-1307. https://doi.org/10.1126/science.1210944.

[150] Ito S., Shen L., Dai Q., Wu S. C., Collins L. B., Swenberg J. A., He C., Zhang Y. (2011). Tet proteins can convert 5-methylcytosine to 5-formylcytosine and 5-carboxylcytosine. Science. 333, 1300-1303. https://doi.org/10.1126/science.1210597.

[151] Maiti A., Drohat A. C. (2011). Thymine DNA glycosylase can rapidly excise 5formylcytosine and 5-carboxylcytosine: potential implications for active demethylation of $\mathrm{CpG}$ sites. J Biol Chem. 286, 35334-35338. https://doi.org/10.1074/jbc.C111.284620.

[152] Cortellino S., Xu J., Sannai M., Moore R., Caretti E., Cigliano A., Le Coz M., Devarajan K., Wessels A., Soprano D., Abramowitz L. K., Bartolomei M. S., Rambow F., Bassi M. R., Bruno T., Fanciulli M., Renner C., Klein-Szanto A. J., Matsumoto Y., Kobi D., Davidson I., Alberti C., Larue L., Bellacosa A. (2011). Thymine DNA glycosylase is essential for active DNA demethylation by linked deamination-base excision repair. Cell. 146, 67-79. https://doi.org/10.1016/j.cell.2011.06.020.

[153] Wossidlo M., Arand J., Sebastiano V., Lepikhov K., Boiani M., Reinhardt R., Scholer H., Walter J. (2010). Dynamic link of DNA demethylation, DNA strand breaks and repair in mouse zygotes. EMBO J. 29, 1877-1888. https://doi.org/10.1038/emboj.2010.80.

[154] Hajkova P., Jeffries S. J., Lee C., Miller N., Jackson S. P., Surani M. A. (2010). Genomewide reprogramming in the mouse germ line entails the base excision repair pathway. Science. 329, 78-82. https://doi.org/10.1126/science.1187945.

[155] Krishnakumar R., Gamble M. J., Frizzell K. M., Berrocal J. G., Kininis M., Kraus W. L. (2008). Reciprocal binding of PARP-1 and histone $\mathrm{H} 1$ at promoters specifies transcriptional outcomes. Science. 319, 819-821. https://doi.org/10.1126/science.1149250.

[156] Nalabothula N., Al-jumaily T., Eteleeb A. M., Flight R. M., Xiaorong S., Moseley H., Rouchka E. C., Fondufe-Mittendorf Y. N. (2015). Genome-Wide Profiling of PARP1 Reveals an Interplay with Gene Regulatory Regions and DNA Methylation. PLoS One. 10, e0135410. https://doi.org/10.1371/journal.pone.0135410.

[157] Qin W., Wolf P., Liu N., Link S., Smets M., La Mastra F., Forne I., Pichler G., Horl D., Fellinger K., Spada F., Bonapace I. M., Imhof A., Harz H., Leonhardt H. (2015). DNA methylation requires a DNMT1 ubiquitin interacting motif (UIM) and histone ubiquitination. Cell Res. 25, 911-929. https://doi.org/10.1038/cr.2015.72.

[158] Loo S. K., Ab Hamid S. S., Musa M., Wong K. K. (2018). DNMT1 is associated with cell cycle and DNA replication gene sets in diffuse large B-cell lymphoma. Pathol Res Pract. 214, 134-143. https://doi.org/10.1016/j.prp.2017.10.005.

[159] Zampieri M., Passananti C., Calabrese R., Perilli M., Corbi N., De Cave F., Guastafierro T., Bacalini M. G., Reale A., Amicosante G., Calabrese L., Zlatanova J., Caiafa P. (2009). Parp1 localizes within the Dnmt1 promoter and protects its unmethylated state by its enzymatic activity. PLoS One. 4, e4717. https://doi.org/10.1371/journal.pone.0004717. 
[160] Zampieri M., Guastafierro T., Calabrese R., Ciccarone F., Bacalini M. G., Reale A., Perilli M., Passananti C., Caiafa P. (2012). ADP-ribose polymers localized on Ctcf-Parp1-Dnmt1 complex prevent methylation of Ctcf target sites. Biochem J. 441, 645-652. https://doi.org/10.1042/bj20111417.

[161] De Vos M., El Ramy R., Quenet D., Wolf P., Spada F., Magroun N., Babbio F., Schreiber V., Leonhardt H., Bonapace I. M., Dantzer F. (2014). Poly(ADP-ribose) polymerase 1 (PARP1) associates with E3 ubiquitin-protein ligase UHRF1 and modulates UHRF1 biological functions. J Biol Chem. 289, 16223-16238. https://doi.org/10.1074/jbc.M113.527424.

[162] Becker A., Zhang P., Allmann L., Meilinger D., Bertulat B., Eck D., Hofstaetter M., Bartolomei G., Hottiger M. O., Schreiber V., Leonhardt H., Cardoso M. C. (2016). Poly(ADPribosyl)ation of Methyl CpG Binding Domain Protein 2 Regulates Chromatin Structure. J Biol Chem. 291, 4873-4881. https://doi.org/10.1074/jbc.M115.698357.

[163] Witcher M., Emerson B. M. (2009). Epigenetic silencing of the p16(INK4a) tumor suppressor is associated with loss of CTCF binding and a chromatin boundary. Mol Cell. 34, 271-284. https://doi.org/10.1016/j.molcel.2009.04.001.

[164] Han D., Chen Q., Shi J., Zhang F., Yu X. (2017). CTCF participates in DNA damage response via poly(ADP-ribosyl)ation. Sci Rep. 7, 43530. https://doi.org/10.1038/srep43530.

[165] Pavlaki I., Docquier F., Chernukhin I., Kita G., Gretton S., Clarkson C. T., Teif V. B., Klenova E. (2018). Poly(ADP-ribosyl)ation associated changes in CTCF-chromatin binding and gene expression in breast cells. Biochim Biophys Acta Gene Regul Mech. 1861, 718-730. https://doi.org/10.1016/j.bbagrm.2018.06.010.

[166] Dubois-Chevalier J., Oger F., Dehondt H., Firmin F. F., Gheeraert C., Staels B., Lefebvre P., Eeckhoute J. (2014). A dynamic CTCF chromatin binding landscape promotes DNA hydroxymethylation and transcriptional induction of adipocyte differentiation. Nucleic Acids Res. 42, 10943-10959. https://doi.org/10.1093/nar/gku780.

[167] Marina R. J., Sturgill D., Bailly M. A., Thenoz M., Varma G., Prigge M. F., Nanan K. K., Shukla S., Haque N., Oberdoerffer S. (2016). TET-catalyzed oxidation of intragenic 5methylcytosine regulates CTCF-dependent alternative splicing. EMBO J. 35, 335-355. https://doi.org/10.15252/embj.201593235.

[168] Nanan K. K., Sturgill D. M., Prigge M. F., Thenoz M., Dillman A. A., Mandler M. D., Oberdoerffer S. (2019). TET-Catalyzed 5-Carboxylcytosine Promotes CTCF Binding to Suboptimal Sequences Genome-wide. iScience. 19, 326-339. https://doi.org/10.1016/j.isci.2019.07.041.

[169] Ciccarone F., Valentini E., Bacalini M. G., Zampieri M., Calabrese R., Guastafierro T., Mariano G., Reale A., Franceschi C., Caiafa P. (2014). Poly(ADP-ribosyl)ation is involved in the epigenetic control of TET1 gene transcription. Oncotarget. 5, 10356-10367. https://doi.org/10.18632/oncotarget.1905.

[170] Ciccarone F., Valentini E., Zampieri M., Caiafa P. (2015). 5mC-hydroxylase activity is influenced by the PARylation of TET1 enzyme. Oncotarget. 6, 24333-24347. https://doi.org/10.18632/oncotarget.4476.

[171] Fujiki K., Shinoda A., Kano F., Sato R., Shirahige K., Murata M. (2013). PPARgammainduced PARylation promotes local DNA demethylation by production of 5hydroxymethylcytosine. Nat Commun. 4, e2262. https://doi.org/10.1038/ncomms3262.

[172] Puget N., Miller K. M., Legube G. (2019). Non-canonical DNA/RNA structures during Transcription-Coupled Double-Strand Break Repair: Roadblocks or Bona fide repair intermediates? DNA Repair (Amst). https://doi.org/10.1016/j.dnarep.2019.102661.

[173] Feng W., Chakraborty A. (2017). Fragility Extraordinaire: Unsolved Mysteries of Chromosome Fragile Sites. Adv Exp Med Biol. 1042, 489-526. https://doi.org/10.1007/978981-10-6955-0 21.

[174] Aguilera A., Garcia-Muse T. (2012). R loops: from transcription byproducts to threats to genome stability. Mol Cell. 46, 115-124. https://doi.org/10.1016/j.molcel.2012.04.009.

[175] Ginno P. A., Lott P. L., Christensen H. C., Korf I., Chedin F. (2012). R-loop formation is a distinctive characteristic of unmethylated human CpG island promoters. Mol Cell. 45, 814825. https://doi.org/10.1016/j.molcel.2012.01.017. 
[176] Drolet M. (2006). Growth inhibition mediated by excess negative supercoiling: the interplay between transcription elongation, R-loop formation and DNA topology. Mol Microbiol. 59, 723-730. https://doi.org/10.1111/j.1365-2958.2005.05006.x.

[177] Pommier Y., Sun Y., Huang S. N., Nitiss J. L. (2016). Roles of eukaryotic topoisomerases in transcription, replication and genomic stability. Nat Rev Mol Cell Biol. 17, 703-721. https://doi.org/10.1038/nrm.2016.111.

[178] El Hage A., French S. L., Beyer A. L., Tollervey D. (2010). Loss of Topoisomerase I leads to R-loop-mediated transcriptional blocks during ribosomal RNA synthesis. Genes Dev. 24, 1546-1558. https://doi.org/10.1101/gad.573310.

[179] Cristini A., Ricci G., Britton S., Salimbeni S., Huang S. N., Marinello J., Calsou P., Pommier Y., Favre G., Capranico G., Gromak N., Sordet O. (2019). Dual Processing of RLoops and Topoisomerase I Induces Transcription-Dependent DNA Double-Strand Breaks. Cell Rep. 28, 3167-3181 e3166. https://doi.org/10.1016/j.celrep.2019.08.041.

[180] Ju B. G., Lunyak V. V., Perissi V., Garcia-Bassets I., Rose D. W., Glass C. K., Rosenfeld M. G. (2006). A topoisomerase Ilbeta-mediated dsDNA break required for regulated transcription. Science. 312, 1798-1802. https://doi.org/10.1126/science.1127196.

[181] Soubeyrand S., Pope L., Hache R. J. (2010). Topoisomerase Ilalpha-dependent induction of a persistent DNA damage response in response to transient etoposide exposure. Molecular Oncology. 4, 38-51. https://doi.org/10.1016/j.molonc.2009.09.003.

[182] Puc J., Aggarwal A. K., Rosenfeld M. G. (2017). Physiological functions of programmed DNA breaks in signal-induced transcription. Nat Rev Mol Cell Biol. 18, 471-476. https://doi.org/10.1038/nrm.2017.43.

[183] D'Alessandro G., d'Adda di Fagagna F. (2017). Transcription and DNA Damage: Holding Hands or Crossing Swords? J Mol Biol. 429, 3215-3229. https://doi.org/10.1016/j.jmb.2016.11.002.

[184] Jubin T., Kadam A., Gani A. R., Singh M., Dwivedi M., Begum R. (2017). Poly ADPribose polymerase-1: Beyond transcription and towards differentiation. Semin Cell Dev Biol. 63, 167-179. https://doi.org/10.1016/j.semcdb.2016.07.027.

[185] Stilmann M., Hinz M., Arslan S. C., Zimmer A., Schreiber V., Scheidereit C. (2009). A nuclear poly(ADP-ribose)-dependent signalosome confers DNA damage-induced lkappaB kinase activation. Mol Cell. 36, 365-378. https://doi.org/10.1016/j.molcel.2009.09.032.

[186] Izhar L., Adamson B., Ciccia A., Lewis J., Pontano-Vaites L., Leng Y., Liang A. C., Westbrook T. F., Harper J. W., Elledge S. J. (2015). A Systematic Analysis of Factors Localized to Damaged Chromatin Reveals PARP-Dependent Recruitment of Transcription Factors. Cell Rep. 11, 1486-1500. https://doi.org/10.1016/j.celrep.2015.04.053.

[187] Awwad S. W., Abu-Zhayia E. R., Guttmann-Raviv N., Ayoub N. (2017). NELF-E is recruited to DNA double-strand break sites to promote transcriptional repression and repair. EMBO Rep. 18, 745-764. https://doi.org/10.15252/embr.201643191.

[188] Gibson B. A., Zhang Y., Jiang H., Hussey K. M., Shrimp J. H., Lin H., Schwede F., Yu Y., Kraus W. L. (2016). Chemical genetic discovery of PARP targets reveals a role for PARP1 in transcription elongation. Science. 353, 45-50. https://doi.org/10.1126/science.aaf7865.

[189] Su C. H., Shann Y. J., Hsu M. T. (2009). p53 chromatin epigenetic domain organization and p53 transcription. Mol Cell Biol. 29, 93-103. https://doi.org/10.1128/mcb.00704-08.

[190] Interthal H., Chen H. J., Champoux J. J. (2005). Human Tdp1 cleaves a broad spectrum of substrates, including phosphoamide linkages. J Biol Chem. 280, 36518-36528. https://doi.org/10.1074/jbc.M508898200.

[191] Das B. B., Huang S. Y., Murai J., Rehman I., Ame J. C., Sengupta S., Das S. K., Majumdar P., Zhang H., Biard D., Majumder H. K., Schreiber V., Pommier Y. (2014). PARP1TDP1 coupling for the repair of topoisomerase I-induced DNA damage. Nucleic Acids Res. 42, 4435-4449. https://doi.org/10.1093/nar/gku088.

[192] Lonskaya I., Potaman V. N., Shlyakhtenko L. S., Oussatcheva E. A., Lyubchenko Y. L., Soldatenkov V. A. (2005). Regulation of poly(ADP-ribose) polymerase-1 by DNA structurespecific binding. J Biol Chem. 280, 17076-17083. https://doi.org/10.1074/jbc.M413483200.

[193] Day T. A., Layer J. V., Cleary J. P., Guha S., Stevenson K. E., Tivey T., Kim S., Schinzel A. C., Izzo F., Doench J., Root D. E., Hahn W. C., Price B. D., Weinstock D. M. (2017). PARP3 
is a promoter of chromosomal rearrangements and limits G4 DNA. Nat Commun. 8, 15110. https://doi.org/10.1038/ncomms15110.

[194] Liu Y., Sharpless N. E. (2009). Tumor suppressor mechanisms in immune aging. Curr Opin Immunol. 21, 431-439. https://doi.org/10.1016/j.coi.2009.05.011.

[195] Shivakumar L., Minna J., Sakamaki T., Pestell R., White M. A. (2002). The RASSF1A tumor suppressor blocks cell cycle progression and inhibits cyclin D1 accumulation. Mol Cell Biol. 22, 4309-4318. https://doi.org/10.1128/mcb.22.12.4309-4318.2002.

[196] Donninger H., Clark J., Rinaldo F., Nelson N., Barnoud T., Schmidt M. L., Hobbing K. R., Vos M. D., Sils B., Clark G. J. (2015). The RASSF1A tumor suppressor regulates XPAmediated DNA repair. Mol Cell Biol. 35, 277-287. https://doi.org/10.1128/mcb.00202-14.

[197] Haffner M. C., Aryee M. J., Toubaji A., Esopi D. M., Albadine R., Gurel B., Isaacs W. B., Bova G. S., Liu W., Xu J., Meeker A. K., Netto G., De Marzo A. M., Nelson W. G., Yegnasubramanian S. (2010). Androgen-induced TOP2B-mediated double-strand breaks and prostate cancer gene rearrangements. Nat Genet. 42, 668-675. https://doi.org/10.1038/ng.613.

[198] Kim D. S., Camacho C. V., Nagari A., Malladi V. S., Challa S., Kraus W. L. (2019). Activation of PARP-1 by snoRNAs Controls Ribosome Biogenesis and Cell Growth via the RNA Helicase DDX21. Mol Cell. 75, 1270-1285 e1214. https://doi.org/10.1016/j.molcel.2019.06.020.

[199] Rass U., Ahel I., West S. C. (2007). Actions of aprataxin in multiple DNA repair pathways. J Biol Chem. 282, 9469-9474. https://doi.org/10.1074/jbc.M611489200.

[200] Harris J. L., Jakob B., Taucher-Scholz G., Dianov G. L., Becherel O. J., Lavin M. F. (2009). Aprataxin, poly-ADP ribose polymerase 1 (PARP-1) and apurinic endonuclease 1 (APE1) function together to protect the genome against oxidative damage. Hum Mol Genet. 18, 4102-4117. https://doi.org/10.1093/hmg/ddp359.

[201] Gueven N., Becherel O. J., Kijas A. W., Chen P., Howe O., Rudolph J. H., Gatti R., Date H., Onodera O., Taucher-Scholz G., Lavin M. F. (2004). Aprataxin, a novel protein that protects against genotoxic stress. Hum Mol Genet. 13, 1081-1093. https://doi.org/10.1093/hmg/ddh122.

[202] Crawford K., Bonfiglio J. J., Mikoc A., Matic I., Ahel I. (2018). Specificity of reversible ADP-ribosylation and regulation of cellular processes. Crit Rev Biochem Mol Biol. 53, 64-82. https://doi.org/10.1080/10409238.2017.1394265. 


\section{FIGURE LEGENDS}

Fig. 1. An overview of substrates, sites and products of ADP-ribosyltrasferases.

Fig. 2. ADPr recognizing domains

Fig. 3. Schematic representation of the DNA damage-induced ADP-ribosylation and transcription. Prior to transcriptional initiation, DNA is nicked by topoisomerases and/or nucleases introducing SSBs and DSBs. Upon DNA damage, PARP1 (possibly PARP2, PARP3, or other PARPs) will be activated and recruited to the damage site. PARPs ADP. ribosylate themselves, potentially DNA termini, histones, and other proteins, block DNMT1 activity, and recruit DNA repair proteins and transcription factors to the DNA damage sites in the promoter or enhancer region. Then, the affected chromatin decondenses, DNA gets demethylated, and transcription starts. After restoration of DNA integrity and potentially of the methylation pattern, transcription can be blocked again.

Fig. 4. Schematic representation of the cellular responses to programmed and random DNA strand breaks. 
Target

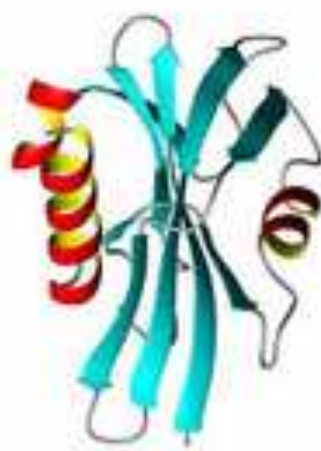

Proteins

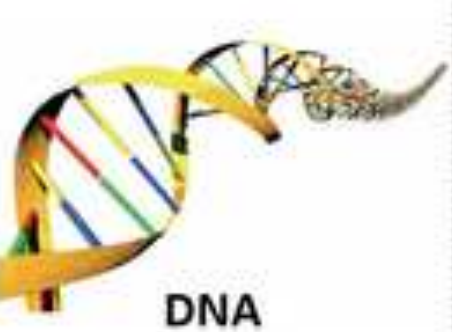

DNA

RNA

ADP-ribose acceptor residues

Type of modification

ADP-ribosyltransferases

PARPs, ARTCs, sirtuins, pertussis toxin Cysteine Asparagine Diphthamide Histidine Tyrosine

Guanine Thymine terminal $3^{\prime}$ - or 5'phosphate 2' OH

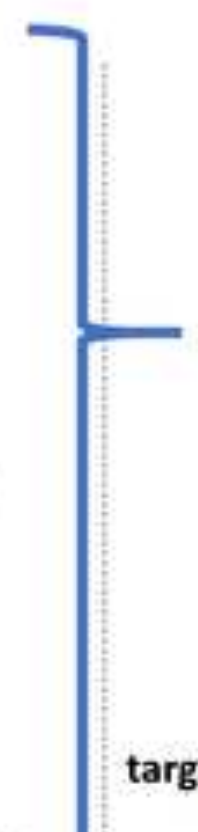

mono-, oligo- or polyADP-ribose

linear or branched

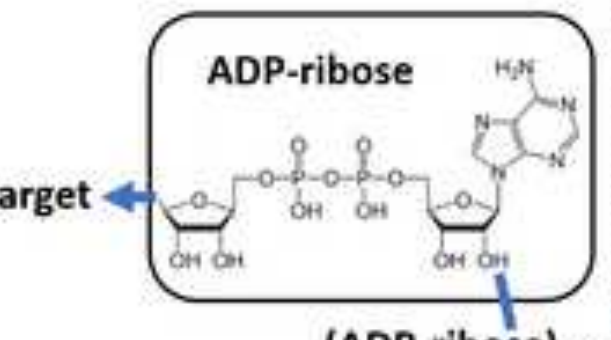

(ADP-ribose) $)_{n}$

$$
\mathbf{n} \leq \mathbf{2 0 0}
$$

mono-ADP-ribose

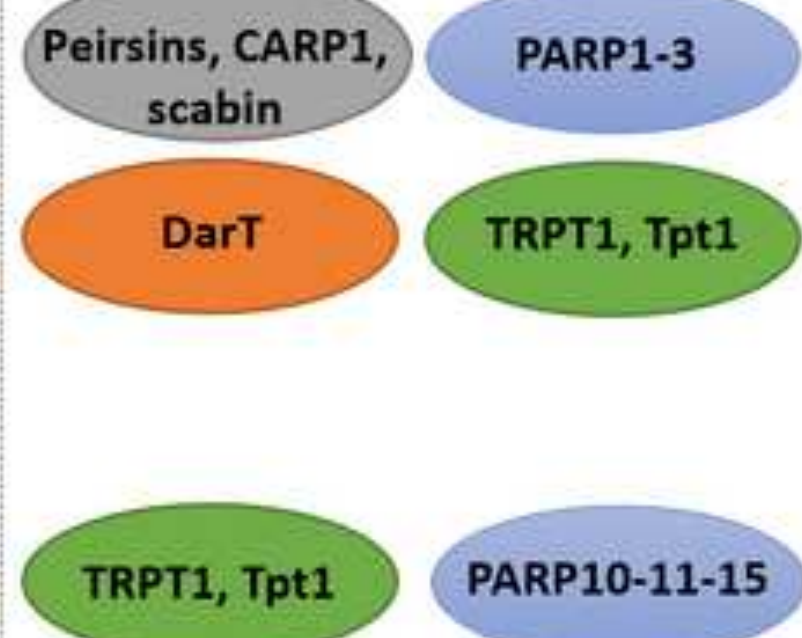

5'-phosphate

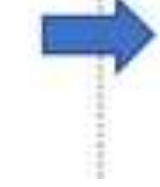




\section{ADPr recognizing domains}

$\begin{array}{cc}\begin{array}{c}\text { (ADPr })_{n} \\ \text { PBM }\end{array} & \begin{array}{c}\text { Terminal ADPr } \\ \text { Macro }\end{array} \\ \begin{array}{c}\text { iso-ADPr } \\ \text { FHA, WWE, OB-fold }\end{array} & \begin{array}{c}\text { Phosphate of }(\text { ADPr })_{n} \\ \text { BRCT }\end{array} \\ & \text { Two consecutive ADPr } \\ \text { PBZ } & \\ \text { (ADPr })_{n} \text { as DNA, RNA or a } \\ \text { nucleotide counterpart } \\ \text { RRM, GAR, PIN }\end{array}$

\section{Target-specific ADPr readers}

Protein-(ADPr)

Amino acid-(ADPr) $)_{n}$

?

DNA-phosphate-(ADPr) $)_{n}$

?

DNA-base-ADPr

RNA-phosphate-(ADPr) 


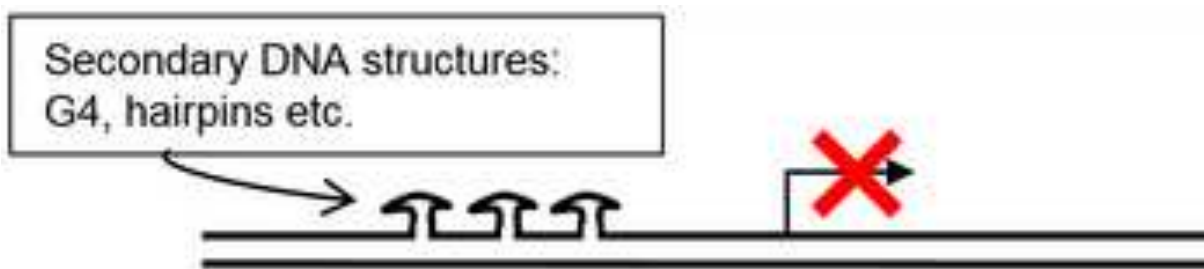

TOP2, TOP1, AID, CAD
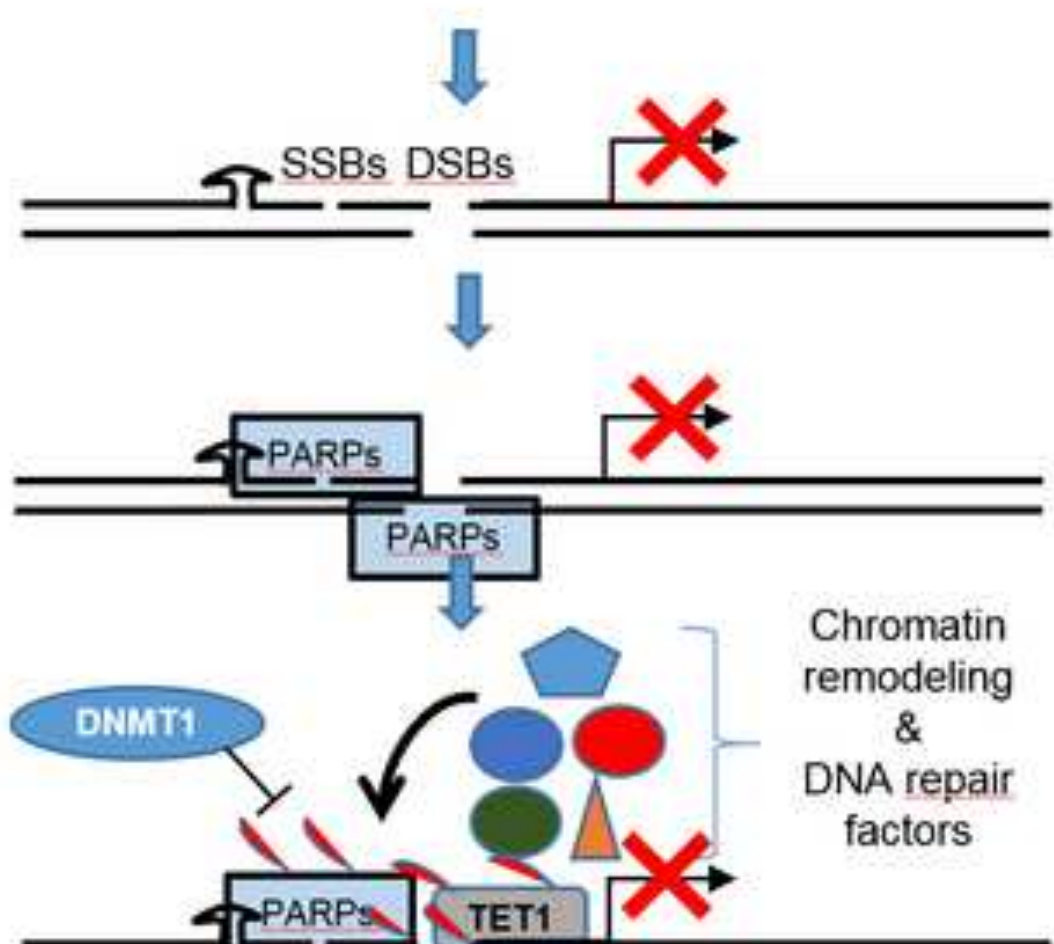

Chromatin remodeling \&

DNA repair factors

hypomethylated DNA

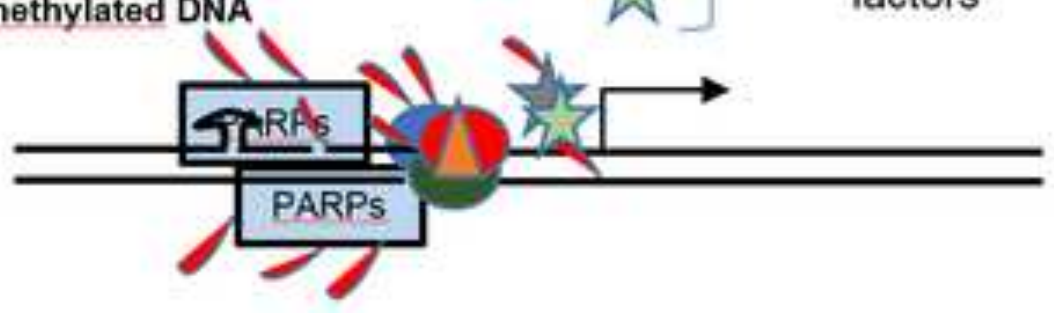

Formation of DNA breaks:

- SSBS

- DSBS

- Early DNA damage recognition by PARPS (mainly PARP1-3):

- Protein (and DNA ?) ADP-ribosylation

- Chromatin modification \& remodeling

- Recruitment of DNA repair factors

- DNA damage processing

- DNMT1 inhibition and TET1 loading

- DNA demethylation

- Recruitment of transcription factors

- Transcription activation 


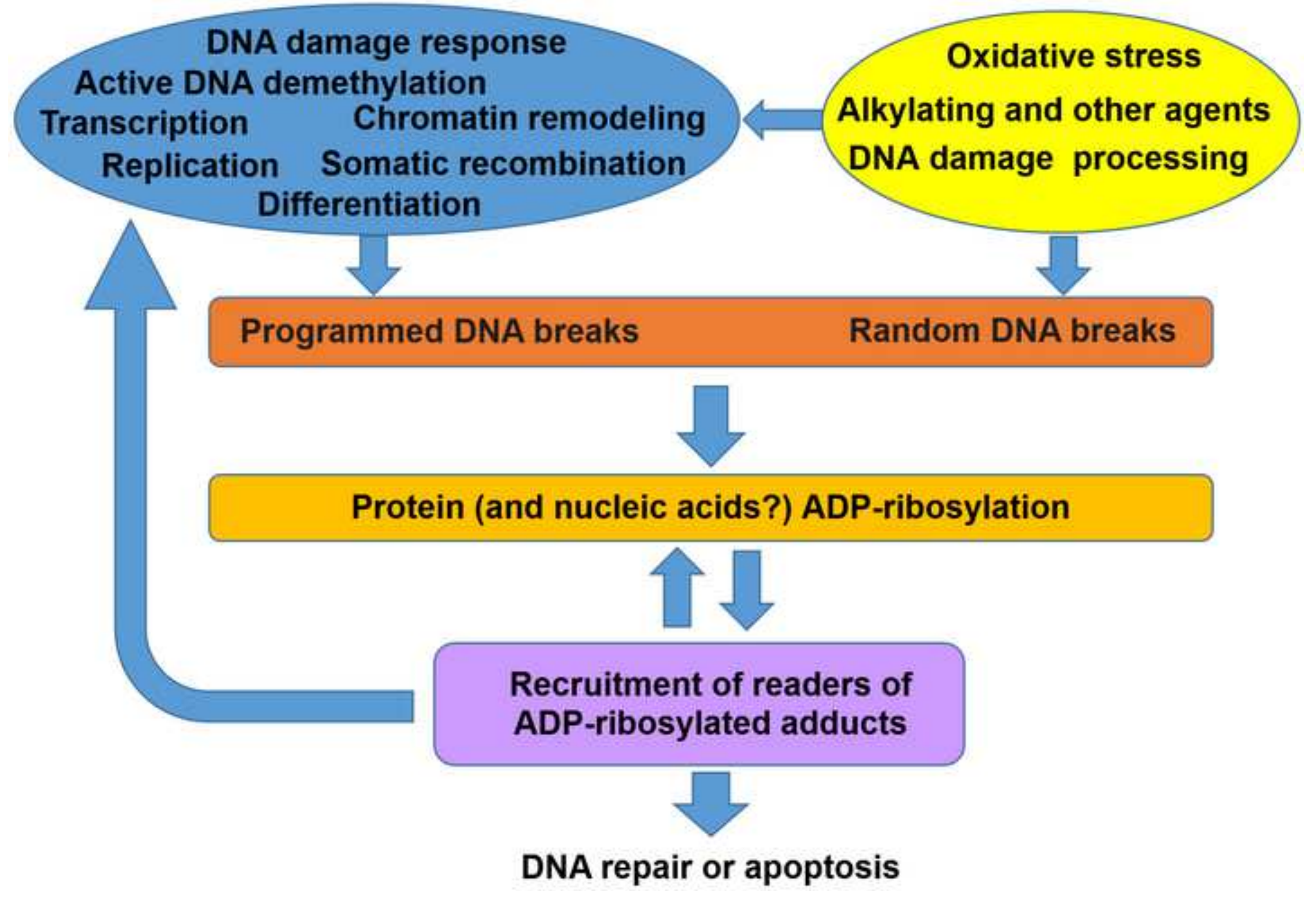

Recruitment of readers of

DNA repair or apoptosis

Active DNA demethylation

Transcription

Differentiation

\section{Oxidative stress} Alkylating and other agents DNA damage processing 